\title{
TITLE: Nucleosome conformation dictates the histone code
}

AUTHORS: Matthew R. Marunde ${ }^{1, \dagger}$, Harrison A. Fuchs $s^{2,3, \dagger}$, Jonathan M. Burg ${ }^{1}$, Irina K.

Popova $^{1}$, Anup Vaidya ${ }^{1}$, Nathan W. Hall ${ }^{1}$, Matthew J. Meiners ${ }^{1}$, Rachel Watson ${ }^{1}$, Sarah A.

Howard $^{1}$, Katherine Novitzky ${ }^{1}$, Eileen McAnarney ${ }^{1}$, Marcus A. Cheek ${ }^{1}$, Zu-Wen Sun ${ }^{1}$, Bryan J.

Venters $^{1}$, Michael-C. Keogh ${ }^{1, *}$ and Catherine A. Musselman ${ }^{2,3, *}$

\section{ADDRESSES}

${ }^{1}$ EpiCypher Inc., Durham NC 27709, USA

${ }^{2}$ Dept. of Biochemistry, University of Iowa Carver College of Medicine, Iowa City IA 52242, USA

${ }^{3}$ Dept. of Biochemistry and Molecular Genetics, University of Colorado Anschutz Medical Campus, Aurora CO 80045, USA

$\dagger$ These authors contributed equally to this work

*Correspondence: mkeogh@epicypher.com, catherine.musselman@cuanschutz.edu

KEYWORDS: Histone code, histone post-translational modifications, histone PTMs, histone peptides, reader domain, semi-synthetic nucleosomes.

ABBREVIATIONS: BD, Bromodomain; BPTF, Bromodomain PHD Finger Transcription

Factor; CAP, Chromatin Associated Protein; CSP, Chemical shift perturbation; Nuc,

Nucleosome; PTM, Post-Translational Modification.

ABSTRACT COUNT: 158 words

MANUSCRIPT COUNT: 4077 words 


\begin{abstract}
Histone post-translational modifications (PTMs) play a critical role in chromatin regulation. It has been proposed that these PTMs form localized 'codes' that are read by specialized regions (reader domains) in chromatin associated proteins (CAPs) to regulate downstream function. Substantial effort has been made to define [CAP-histone PTM] specificity, and thus decipher the histone code / guide epigenetic therapies. However, this has largely been done using a reductive approach of isolated reader domains and histone peptides, with the assumption that PTM readout is unaffected by any higher order factors. Here we show that CAP-histone PTM interaction is in fact dependent on nucleosome context. Our results indicate this is due to histone tail accessibility and the associated impact on binding potential of reader domains. We further demonstrate that the in vitro specificity of a tandem reader for PTM-defined nucleosomes is recapitulated in a cellular context. This necessitates we refine the 'histone code' concept and interrogate it at the nucleosome level.
\end{abstract}

The eukaryotic genome exists in the cell nucleus in the form of chromatin, a complex between DNA and histone proteins. The basic repeating chromatin subunit is the nucleosome (hereafter Nuc): an octamer of core histones (two each of H2A, H2B, H3, and H4) wrapped by $\sim 147$ base pairs of DNA (Fig. 1a) ${ }^{1}$. Chromatin organization is critical for regulation of the underlying genome and is spatially and temporally controlled throughout development and within somatic cells. One of the major mechanisms to modulate chromatin structure is post-translational modification (PTM) of the histone proteins, particularly on their N-terminal and C-terminal tails (Fig. 1a). Globally speaking, particular histone PTMs are correlated with distinct chromatin states (e.g. transcriptional activation/repression, damaged DNA) and genomic elements (e.g. gene enhancers, centromeres $)^{2-4}$. Importantly, it has been proposed that histone PTMs function in

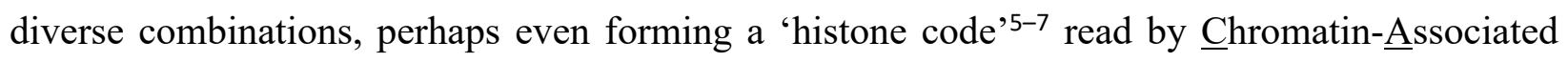
Proteins (CAPs) via their various 'reader domains', thus localizing and/or regulating CAP activity $^{8,9}$. However, the dictates of such a code and role that reader domains play in mediating same is hotly debated, as it has been challenging to: determine the pattern of PTMs read out by tandem domains in vitro, determine whether this pattern is actually being discerned in the in vivo context, and finally determine if this leads to a unique biological outcome ${ }^{10}$. Resolving this situation is critical not only to define the fundamentals of the histone code, but also as efforts ramp 
up to utilize PTM patterns in disease diagnostics and therapeutically target CAP-PTM associations $^{11-14}$.

As a starting point, it is critical to clearly establish the PTM patterns actually engaged by reader domains. To date, the in vitro specificity of individual readers has almost exclusively been determined using modified histone tail peptides ${ }^{9,15,16}$. However, this approach provides no insight as to any effect of Nuc context. Moreover, our understanding of the selectivity for PTM patterns can only be inferred as a simple sum of the specificity for individual reader domains, again ignoring any effect of Nuc context ${ }^{15,17}$. Many enzymes that act on the histone tails (e.g. lysine demethylases / methyltransferases) show altered activity when comparing peptide and Nuc substrates $^{18-22}$, suggesting the importance of the higher order environment. Similarly, several studies indicate that reader domains have altered affinity for histone tails in the Nuc context ${ }^{23-26}$. Thus, an essential question arises; does Nuc context alter histone PTM pattern readout? Here we show this is indeed the case, with not only affinity but also specificity impacted for each individual and a tandem of reader domains. We find an overall decrease in the affinity of each reader for histone tails, and a change in their preferred PTM pattern on Nucs versus peptides. Our results support this is largely due to accessibility in the Nuc context, in which histone tails must be displaced from DNA to enable PTM readout. This alters the engagement of individual domains and the multivalent activity of the tandem domains. We propose that the 'histone code' is ultimately defined by a combination of three elements: 1) the PTMs that can be recognized and bound by individual reader domains; 2) accessibility of the modified histone tails in the Nuc context; and, 3) the organization and multivalent binding potential of grouped domains (where the whole is greater than the sum of the parts).

\section{BPTF PHD-BD demonstrates restricted specificity and synergistic binding in the Nuc context}

The BPTF subunit is important for chromatin association of the NURF (Nucleosome Remodeling Factor) complex ${ }^{27,28}$, and is a pro-tumorigenic factor in several malignancies ${ }^{29}$. At the BPTF C-terminus is a tandem of reader domains: a PHD finger and bromodomain (PHD-BD, Fig. 1b). These are of interest for targeted therapeutics ${ }^{30}$, and so an understanding of their function is critical. In the context of histone peptides, the PHD finger (PHD) has been shown to associate with $\mathrm{H} 3$ tri-methylated at lysine $4(\mathrm{H} 3 \mathrm{~K} 4 \mathrm{me} 3)^{28}$, while the bromodomain $(\mathrm{BD})$ binds to histone tails 
containing acetylated lysines, with a preference for the acetylated H4 tail ${ }^{31-33}$. While some efforts have been made to investigate the recruitment of BPTF PHD-BD to modified Nucs, only a limited subset of $\mathrm{H} 3 \mathrm{~K} 4 \mathrm{me} 3 / \mathrm{H} 4 \mathrm{Kac}$ combinations based on peptide data have been tested, suggesting a preference for $\left[\mathrm{H} 3 \mathrm{~K} 4 \mathrm{me} 3 / \mathrm{H} 4 \mathrm{~K} 5 \mathrm{acK} 8 \mathrm{acK} 12 \mathrm{acK} 16 \mathrm{ac}\right.$ (hereafter H4tetra $\left.\left.{ }^{\mathrm{ac}}\right)\right]^{33}$ or $[\mathrm{H} 3 \mathrm{~K} 4 \mathrm{me} 3$ / $\mathrm{H} 4 \mathrm{~K} 16 \mathrm{ac}]^{33,34}$.

To more comprehensively investigate if Nuc context alters the BPTF PHD-BD readout of histone PTMs, we utilized the $d$ Cypher $^{\circledR}$ approach $^{35}$ (dCypher for brevity) on the Alpha ${ }^{\circledR}$ platform $^{36,37}$ (Extended Data Fig. 1a and Suppl. Discussion) to screen GST- and 6His- tagged forms of the tandem reader (GST-PHD-BD and 6His-PHD-BD; see Suppl. Discussion) against large panels of biotinylated PTM-defined peptides (287×) and Nucs (59×) (Methods and Suppl. Tables 3: Resources A-C). This no-wash bead-based proximity assay allows measurement of the relative $\mathrm{EC}_{50}\left(\mathrm{EC}_{50}{ }^{\mathrm{rel}}\right)$ between Queries : Targets (i.e. readers : histone PTMs) by plotting Alpha Counts (fluorescence) as a function of protein concentration ${ }^{35}$ (see Suppl. Tables $1 \& 2$ for all $\mathrm{EC}_{50}{ }^{\text {rel }}$ from this study).

In agreement with previous studies, the GST-PHD-BD Query showed strong selectivity for methylated H3K4 peptides over all other methyl-residues represented (me1-2-3 at H3K9, H3K27, H3K36, and H4K20: Extended Data Fig. 1b). Also in agreement with previous data, GST-PHDBD demonstrated a preference for acetylated H4 tail peptides (Fig. 1c,e and Extended Data Fig. 1b), although we observed little difference in binding to a multiply acetylated H4 tail versus any of the singly acetylated residues (Extended Data Fig. 1b). We also observed comparable binding to singly or multiply acetylated H3 tail peptides, though with approximately two-fold weaker $\mathrm{EC}_{50}{ }^{\text {rel }}$ as compared to H4 (Fig. 1c,e and Extended Data Fig. 1b). Similar results to these targets were obtained with a 6His-PHD-BD Query (see Suppl. Discussion). Finally, we observed no preference for a $\mathrm{H} 3 \mathrm{~K} 4 \mathrm{me} 3 \mathrm{~K} 9 \mathrm{acK} 14 \mathrm{acK} 18 \mathrm{ac}$ (hereafter $\mathrm{H} 3 \mathrm{~K} 4 \mathrm{me} 3 \mathrm{tri}^{\mathrm{ac}}$ ) peptide over those containing each PTM class alone, in agreement with a recent study ${ }^{38}$ (Fig. 1c,e). Thus, peptides provide no support for a 'histone code' model, in which multivalent engagement by PHD-BD with a cognate combinatorially modified substrate would be expected to manifest as stronger binding than engagement of either domain alone.

We next examined interaction of the GST-PHD-BD Query with PTM-defined Nucs and found several striking differences. First, the overall affinity for Nucs was reduced relative to peptides (Fig. 1c-e). Second, binding of GST-PHD-BD to Nucs recapitulated only a subset of the 
interactions observed with peptides (Fig. 1c-e and Extended Data Fig. 1b,c). The differences included a selectivity for H3K4me3 over the me2 / me1 states (Extended Data Fig. 1d,e), and binding to acetylated H3 but not acetylated H4 (Fig. 1d,e and Extended Data Fig. 1b,c). A third contrast to peptides was a dramatic increase in the GST-PHD-BD affinity for Nucs containing the $\mathrm{H} 3 \mathrm{~K} 4 \mathrm{me} 3 \mathrm{tri}^{\mathrm{ac}}$ combinatorial pattern versus those containing each PTM class alone (26-fold over H3K4me3; 20-fold over H3K4acK9acK14acK18ac (hereafter H3tetra ${ }^{\text {ac }}$ )) (Fig. 1d,e). This last point would support a 'histone code' where reader domains act synergistically to engage preferred PTM patterns.

To further refine the PTM patterns recognized by GST-PHD-BD in the Nuc context, we explored additional H3 methyl / acetyl combinations (Extended Data Fig. 1f,g). Here the Query bound with similar $\mathrm{EC}_{50}{ }^{\text {rel }}$ to $\mathrm{H} 3 \mathrm{~K} 4 \mathrm{me} 3$ tri $^{\mathrm{ac}}$, $\mathrm{H} 3 \mathrm{~K} 4 \mathrm{me} 3 \mathrm{~K} 14 \mathrm{ac}$, and $\mathrm{H} 3 \mathrm{~K} 4 \mathrm{me} 3 \mathrm{~K} 18 \mathrm{ac}$, but substantially weaker to H3K4me3K9ac. Notably, crystal structures of BPTF BD in complex with acetylated histone peptides ${ }^{33}$ indicate that the bromodomain binding pocket can only accommodate one acetyl-lysine. Thus, data supports that in the Nuc context, PHD-BD preferentially reads out H3K4me3K14ac or H3K4me3K18ac.

\section{Individual domains have reduced affinity and altered specificity in the Nuc context}

To gain further insight into the contribution of each domain to the synergistic binding of PHD-BD, we tested their individual reader ability for peptides and Nucs. As for the tandem PHDBD Query, the relative affinity of 6His-PHD was reduced for Nucs relative to peptides (Extended Data Fig. 2a-d and Suppl. Tables 1 \& 2). Interestingly, while on peptides 6His-PHD preferentially associated with $\mathrm{H} 3 \mathrm{~K} 4 \mathrm{me} 3$ with approximately two-fold weaker $\mathrm{EC}_{50}{ }^{\text {rel }}$ for H3K4me3tri ${ }^{\text {ac }}$ (Extended Data Fig. 2a,c), this relationship was inverted for Nucs (Extended Data Fig. 2b,d). The same general affinity trends were observed for the GST-PHD Query (Extended Data Fig. 2b,e and Suppl. Discussion). Of particular note, in testing methyl / single acetyl combinatorial Nucs GST-PHD had stronger binding with a co-incident acetyl present, but demonstrated a similar $\mathrm{EC}_{50}{ }^{\text {rel }}$ for K9ac, K14ac or K18ac (Extended Data Fig. 2b,e). This was a striking contrast to the interaction of tandem GST-PHD-BD with Nucs, where H3K9ac did not contribute to an improved $\mathrm{EC}_{50}{ }^{\text {rel }}$. In agreement with previous studies ${ }^{33}$, 6 His-BD alone bound both acetylated H3 and H4 peptides, but with a preference for acetylated H4 (Extended Data Fig. 
2a,f). However when presented with Nucs, 6His-BD showed no detectable binding to any tested targets (Extended Data Fig. 2b,g).

From above, Nuc context has a substantial (and unexpected) impact on the interaction of the individual PHD and BD with modified histone tails. PHD alone requires the combination of H3K4 methylation and H3 tail acetylation (K9ac, K14ac, K18ac), but does not discern between individual acetylated residues (see Discussion). BD alone cannot associate with any acetylated Nuc substrates, but requires the endogenously partnered PHD to engage the H3 tail independent of its methylation. However, the presence of $\mathrm{BD}$ in the tandem construct confers specificity for H3K14ac and H3K18ac (Extended Data Fig. 1g).

\section{Both domains are required for full activity of the tandem module}

To further investigate the contribution of each domain to binding in the tandem context, we created individual loss-of-function mutants of either PHD (aromatic cage W2891A; PHD ${ }^{\text {mut }}$ ) or BD (ZA-loop N3007A; BD ${ }^{\text {mut }}$ ) (Suppl. Tables 3: Resources A) for dCypher testing. Mutation of W2891 has no impact on PHD structure but abrogates binding to H3K4me3 peptides ${ }^{27,28}$; mutation of $\mathrm{N} 3007$ has no impact on the BD fold but dramatically reduces binding to acetylated peptides (Fig. 2a and Extended Data Fig. 3). Of note, GST-PHD ${ }^{\text {mut }}$ BD lost binding to all tested Nucs $\left(\mathrm{H} 3 \mathrm{~K} 4 \mathrm{me} 3\right.$, H3tetra ${ }^{\mathrm{ac}}$, or $\left.\mathrm{H} 3 \mathrm{~K} 4 \mathrm{me} 3 \mathrm{tri}^{\mathrm{ac}}\right)$. This is consistent with the individual domain activity and revealed that even in the tandem context an active BD is insufficient to mediate Nuc binding without a functional PHD (Fig. 2b,c). In contrast, GST-PHD-BD ${ }^{\text {mut }}$ retained Nuc engagement if provided methylated H3K4: i.e. binding $\mathrm{H} 3 \mathrm{~K} 4 \mathrm{me} 3$ and $\mathrm{H} 3 \mathrm{~K} 4 \mathrm{me} 3 \mathrm{tri}^{\mathrm{ac}}$ but not H3tetra $^{\text {ac }}$ (Fig. 2b,c). Together this indicates that the PHD is critical for association with all Nuc targets, even when $\mathrm{H} 3 \mathrm{~K} 4$ is not methylated. In contrast BD contributes to Nuc binding only when $\mathrm{H} 3$ is acetylated.

\section{The PHD-BD makes multivalent contacts with the acetylated $\mathrm{H3}$ tail}

Above results suggest that both reader domains support the association of the tandem PHDBD with the acetylated H3 tail independent of methylation state, whereas the BD may only associate with the acetylated $\mathrm{H} 4$ tail in a peptide format. To further investigate this, we turned to NMR spectroscopy. Sequential ${ }^{1} \mathrm{H},{ }^{15} \mathrm{~N}-\mathrm{HSQC}$ spectra were recorded on ${ }^{15} \mathrm{~N}$-labeled PHD-BD upon addition of unlabeled histone peptides corresponding to $\mathrm{H} 3 \mathrm{tri}^{\mathrm{ac}}$, H3tetra ${ }^{\mathrm{ac}}$, or $\mathrm{H} 3 \mathrm{~K} 4 \mathrm{me} 3 \operatorname{tri}^{\mathrm{ac}}$ 
(Fig. 3a and Extended Data Fig. 4). Chemical shift perturbations (CSPs) were observed in BD resonances upon addition of all three peptides, indicating ligand engagement. The bound state chemical shift for BD resonances was similar for all three peptide substrates, suggesting a mechanism of BD association independent of the H3K4 modification state (Fig. 3a). CSPs were also seen in resonances for the PHD finger upon addition of all three substrates, but with unique bound state chemical shifts dependent on the H3K4 modification state. Specifically, H3tetra ${ }^{\text {ac }}$ and H3K9acK14acK18ac (H3tri $\left.{ }^{\text {ac }}\right)$ led to nearly identical bound state chemical shifts, contrasting with the unique signatures of $\mathrm{H} 3 \mathrm{~K} 4 \mathrm{me} 3$ tria $^{\text {ac }}$ (Fig. 3a) Together this reveals that the PHD-BD associates with the acetylated $\mathrm{H} 3$ tail in a multivalent manner, employing both domains independent of H3K4 modification status, but forming a unique complex when $\mathrm{H} 3 \mathrm{~K} 4$ is trimethylated.

The PHD/H3 binding interface includes pockets for $\mathrm{H} 3$ residues $\mathrm{A} 1, \mathrm{R} 2$, and $\mathrm{K} 4 \mathrm{me} 3^{28}$ (Fig. 2a), with K4me3 needed for a robust Nuc interaction in the isolated PHD context. From the above NMR data we hypothesized that in the tandem PHD-BD context the A1 and/or R2 interactions (even in the absence of $\mathrm{K} 4 \mathrm{me} 3$ ) contribute to association with the acetylated $\mathrm{H} 3$ tail. To test this, we returned to dCypher and created Nucs with residue truncations at the H3 Nterminus (Fig. 3b), confirming their integrity by an antibody to H3K4me3 (Extended Data Fig. 4d). Upon $\mathrm{H} 3$ A1 deletion (N $\Delta 1$ ) PHD-BD had unmeasurable $\mathrm{EC}_{50}{ }^{\text {rel }}$ (Fig. 3b), indicating that recognition of the histone N-terminus is critical for stable Nuc binding (and consistent with the engagement mechanism for other PHD fingers ${ }^{39}$ ).

\section{DNA interactions occlude histone tail accessibility and lead to altered specificity}

dCypher results showing a dramatically weaker (PHD-BD or PHD only) or undetectable (BD only) $\mathrm{EC}_{50}{ }^{\text {rel }}$ for Query binding to Nucs relative to peptides (e.g. Extended Data Fig. 2) are fully consistent with our previous NMR studies that revealed strong inhibition of PHD binding to $\mathrm{H} 3 \mathrm{~K} 4 \mathrm{me} 3$ in the Nuc context ${ }^{23}$. There we demonstrated that $\mathrm{H} 3$ tail occlusion is due to interactions with nucleosomal $\mathrm{DNA}^{23}$, specifically proposing that the $\mathrm{H} 3$ tails adopt a high-affinity fuzzy complex driven largely by $\mathrm{R} / \mathrm{K}$ residues ${ }^{23,40}$.

Interaction of the PHD-BD and BD alone with acetylated histone H4 was also abrogated in the Nuc context, despite robust binding to comparable peptides (Fig. 1 and Extended Data Figs. 1 - 2). The H4 tail is K/R-rich, has decreased dynamics in the nucleosome vs. peptide context, and computational models suggest it may also form a fuzzy complex with $\mathrm{DNA}^{41}$. To further 
characterize $\mathrm{H} 4$ tail conformation in the Nuc environment, we utilized NMR spectroscopy to investigate a Nuc containing ${ }^{15} \mathrm{~N}-\mathrm{H} 4$ (see Methods). Due to its large size ( $\left.200 \mathrm{kDa}\right)$ and resultant slow tumbling, it is expected that only very flexible regions (such as the tails) will be NMR observable using this isotope labeling scheme (Fig. 1a). Consistent with previous studies ${ }^{41,42}$ we observed resonances for only 15 of the 101 non-proline amino-acids of full length H4, corresponding to tail residues 1-15 (Fig. 3c). However, this represents only 15/20 possible resonances (assuming fast exchange on the NMR time-scale) for the H4 N-terminal tail (as classified by trypsin accessibility: Fig. $\mathbf{1 a}^{43}$ ). The severe line-broadening observed for residues 1620 (also known as the H4 tail basic patch: Extended Data Fig. 5) indicated this region is likely stably associated with the Nuc core, in agreement with previous structural and biochemical studies $^{44}$. However, the conformation of the observable first 15 residues are less clear.

We next generated the ${ }^{15} \mathrm{~N}-\mathrm{H} 4$ tail in peptide form, allowing us to investigate conformational differences between a free tail and that in the Nuc context (as above). Overlay of the resulting spectra showed that every resonance has CSPs between peptide and Nuc (Fig. 3c), consistent with a different chemical environment for every residue. To determine if this is due to association with DNA, we collected sequential ${ }^{1} \mathrm{H},{ }^{15} \mathrm{~N}-\mathrm{HSQC}$ spectra of the ${ }^{15} \mathrm{~N}$-H4-tail peptide upon addition of unlabeled DNA (Fig. 3d). Notably, CSPs were seen for every resonance, revealing that the $\mathrm{H} 4$ tail bound DNA, and every tail residue is impacted. Overlay of the DNAbound ${ }^{15} \mathrm{~N}-\mathrm{H} 4$ tail spectrum with that for the ${ }^{15} \mathrm{~N}-\mathrm{H} 4-\mathrm{Nuc}$ showed very similar chemical shifts, consistent with the entire H4 tail associating with nucleosomal DNA (Fig. 3e), which is in-line with previous cross-linking studies ${ }^{45-47}$. The differential linewidth of resonances indicates the H4 tail has two distinct dynamic regions: the first 15 residues exchanged quickly between multiple conformations on the DNA, consistent with a fuzzy complex ${ }^{48,49}$; while the basic patch exchanged much more slowly and/or between fewer states, leading to loss of signal. This is distinct from the H3 tail, where every residue experienced the fast dynamics of a fuzzy complex, and may be related to charge distribution and/or relative positioning with the NCP core.

The above data supports that, similar to the H3 tail, H4 tail conformation in the Nuc context occludes accessibility, and potentially explains the loss of BPTF BD and PHD-BD association with acetylated $\mathrm{H} 4$. To investigate if this conformation abrogated all interactions with the $\mathrm{H} 4$ tail we tested an alternate bromodomain Query (GST-BRD4-BD1; Suppl. Tables 3: Resources A) against peptides and Nucs (Extended Data Fig. 6). BRD4-BD1 has previously been shown to 
bind acetylated $\mathrm{H} 4$ tail peptides ${ }^{50}$, and dCypher confirmed the strongest $\mathrm{EC}_{50}{ }^{\text {rel }}$ for $\mathrm{H} 4$ tetra $^{\mathrm{ac}}$ over all peptides tested (Extended Data Fig. 6a,c). BRD4-BD1 also bound H4tetra ${ }^{\text {ac }}$ in the Nuc context, though with weaker affinity than the comparable peptide $\left(\mathrm{EC}_{50}{ }^{\text {rel }}\left[\mathrm{CI}^{95}\right]\right.$ values of $7.4 \mathrm{nM}[7.05$ 7.64] Nuc vs. 0.7 nM [0.64-0.73] peptide; Extended Data Fig. 6b,c). Thus, H4 tail accessibility is reader dependent (as also recently demonstrated for PHIP BD1-BD2 ${ }^{51}$ ), and the ability to bind may rely on several factors including overall affinity or different engagement mechanisms. For instance, BRD4 BD1 (unlike BPTF BD) can associate with $\mathrm{DNA}^{52}$, and such competition may help disengage the $\mathrm{H} 4$ tail from the nucleosome core.

Together, this suggests that to enable association in the Nuc context a reader must be able to displace the modified histone tail from DNA. However, tail accessibility can be enhanced by disrupting the DNA interaction via modification of sidechain charge ${ }^{21,23}$, as where distal acetylation of the H3 tail improved BPTF-PHD engagement with H3K4me3 (Extended Data Fig.

2a-d). Notably, acetylation does not fully release the tail from DNA binding, as PHD still showed weaker association with the methylated/acetylated Nuc relative to peptide. This is consistent with previous studies indicating that acetylation weakens but does not fully disrupt histone tail DNA interactions $^{23,53}$.This may also explain why BPTF-BD alone was insufficient to establish binding with acetylated $\mathrm{H} 3$ and $\mathrm{H} 4$ tails.

\section{PHD-BD drives association of BPTF with the methylated and acetylated $\mathrm{H3}$ tail in vivo}

The above in vitro results indicate that BPTF PHD-BD associates with $\mathrm{H} 3 \mathrm{~K} 4 \mathrm{me} 3 \mathrm{~K} 14 \mathrm{ac}$ or $\mathrm{H} 3 \mathrm{~K} 4 \mathrm{me} 3 \mathrm{~K} 18 \mathrm{ac}$ (or H3K4me3K14acK18ac) in the Nuc context. To investigate if this preference is recapitulated in vivo, we performed CUT\&RUN with antibodies to BPTF, H3K4me3, and H3K18ac (see Methods and Suppl. Tables 3: Resources A) in K562 cells. We observed extensive genomic co-localization of BPTF with each PTM, but the greatest degree of overlap when both are present (Extended Data Fig. 7a-e). As a bulk approach CUT\&RUN is unable to confirm definitive co-enrichment of all elements, with one possible interpretation that our observations are due to distinct sub-populations. We thus designed a new approach (Reader CUT\&RUN; see Methods) where GST-PHD-BD was complexed with an antibody to GST ( $\alpha$-GST) to create a CUT\&RUN compatible reagent. We also developed DNA-barcoded PTM-defined Nucs (unmodified, H3K4me3, H3tetra ${ }^{\text {ac }}$ and $\mathrm{H} 3 \mathrm{~K} 4 \mathrm{me} 3$ tri $^{\mathrm{ac}}$; Fig. 4a) as a spike-in to monitor assay performance and GST-PHD-BD preference in situ. In these controlled studies GST-PHD-BD 
showed a dramatic preference for spike-in Nucs containing the combinatorial signature $\left(\mathrm{H} 3 \mathrm{~K} 4 \mathrm{me} 3 \mathrm{tri}^{\mathrm{ac}}\right.$ ) relative to each PTM alone (six-fold over H3K4me3, 41-fold over H3tetra ${ }^{\text {ac. }}$ Fig. 4b), recapitulating the dCypher observations (e.g. Fig. 1d). The genomic enrichment of GSTPHD-BD further confirmed its combinatorial preference, with binding regions showing extensive overlap with those containing H3K4me3 and H3K18ac (Fig. 4c-d). Together with the spike-in results this is consistent with a synergistic association with both PTMs. Furthemore, the genomic enrichment of GST-PHD-BD was also highly correlated with that of endogenous BPTF (Fig. 4cd), supporting that the tandem readers are sufficient to drive effective in vivo localization.

\section{DISCUSSION}

Taken together, our data indicates that nucleosome context strongly influences reader domain engagement with histone PTMs. Previous studies have noted reduced reader affinity on Nucs relative to histone tail peptides ${ }^{23-26}$, but here we show that the PTM(s) bound may also be restricted (e.g. loss of Nuc H4acetyl binding by the BPTF BD and PHD-BD tandem; Fig. 1c-e and Extended Data Fig. 2a-b, f-g), or the preferred modification pattern may be altered (e.g. the PHD preference for Nucs with H3K4me3 and additional tail acetylation; Fig. 2b,e). We propose this is due (at least in part) to association of the histone tails with nucleosomal DNA. This conformation limits accessibility and leads to competition for the tails between the DNA and reader domain(s). As a result, histone PTMs may play multiple roles; weakening the DNA association to increase access for reader domains, providing a platform for reader domain binding, or both.

As a result of occluded tail conformation in the Nuc context, the multivalent binding of tandem domains is not simply defined by raw potential (i.e. the sum of individually preferred PTMs), but also binding opportunity. For BPTF PHD-BD, this manifests as a nucleosomal restriction on $\mathrm{H} 4 \mathrm{ac}$ tail binding, leaving selectivity for $\mathrm{H} 3 \mathrm{ac}$. We observe multiple ways to combine multivalent contacts across domains, and thus support productive engagement. In the case of the BPTF PHD-BD tandem, the PHD can associate with H3 A1, R2 and K4me3 (Fig. 3a-b), while the BD can bind K14ac and K18ac (Extended Data Fig. 1f-g). Notably, when the H3 tail is only acetylated (as in the H3tetra ${ }^{\text {ac }} \mathrm{Nuc}$ ) the resulting weakening of the tail / DNA interaction combined with BD binding to Kac and PHD finger binding to A1 and R2 together support weak Nuc engagement. Alternatively, for H3K4me3 absent any acetylation, PHD contacts with A1, R2 
and K4me3 also support weak Nuc engagement. Finally, strong binding occurs when H3K4me3 and $\mathrm{H} 3 \mathrm{~K} 14 \mathrm{ac}$ or $\mathrm{H} 3 \mathrm{~K} 18 \mathrm{ac}$ are present, promoting tail displacement and allowing both the PHD and BD to most effectively engage. The preference of BPTF PHD-BD for H3K4me3 with $\mathrm{H} 3 \mathrm{~K} 14 \mathrm{ac}$ or $\mathrm{H} 3 \mathrm{~K} 18 \mathrm{ac}$ over H3K9ac may be due to the in cis proximity of $\mathrm{K} 9$ to $\mathrm{H} 3 \mathrm{~K} 4 \mathrm{me} 3$, restricting BD binding when the PHD finger is engaged. Thus, within a tail displacement model, tandem domains can accommodate multiple distinct PTM signatures to engage modified Nucs. Notably, and as seen here, these may have varying strengths of interaction which in turn may mediate an array of responses within the chromatin landscape, including differences in CAP retention at specific sites, or stabilization at an intermediate modified state.

When moving from the peptide to Nuc context we (and others) consistently observe individual reader domains to show reduced affinity and restricted specificity ${ }^{23-26,35,51}$. An exception to this is readers with intrinsic DNA binding ability, such as the PWWPs. These form multivalent interactions with DNA and histone tails (so peptide studies are often uninformative) ${ }^{54-}$ ${ }^{60}$, but may also act to directly compete for the DNA, thus promoting PTM accessibility on their target tail ${ }^{61}$. Indeed, several mechanisms for modulating histone tail conformation can be imagined $^{40}$. Beyond in cis modification of the target histone tail (as in this study), modification of an adjacent tail may alter the dynamics of the target, such trans-tail crosstalk being recently reported for $\mathrm{H} 3$ and $\mathrm{H} 4{ }^{62}$. Adjacent DNA binding domains within the same protein or complex may also play a role in displacing the target tail from DNA. Alternatively, histone tail accessibility can be modulated by changes to the canonical nucleosome composition, such as hexasomes depleted of one $\mathrm{H} 2 \mathrm{~A}-\mathrm{H} 2 \mathrm{~B}$ dimer ${ }^{63}$.

In reader-CUT\&RUN GST-PHD-BD recapitulated the dCypher preference for spike-in Nucs containing the combinatorial target $\left(\mathrm{H} 3 \mathrm{~K} 4 \mathrm{me} 3 \mathrm{tri}^{\mathrm{ac}}\right)$ over each PTM class alone (Fig. 4b). Furthermore, GST-PHD-BD localization across the genome was highly correlated with regions that also contain H3K4me3, H3K18ac and endogenous BPTF (Figs. 4c-d). Together, this suggests that the combinatorial readout of these PTMs is indeed a discerning factor in the genomic localization of BPTF: the activity of both domains is clearly important to achieve robust interaction, and thus at minimum critical to achieve proper kinetics on chromatin.

In an extended analysis of our genomics data, we considered that full-length BPTF (endogenous) could harbor additional regulatory potential over exogenous BPTF PHD-BD. In this regard while the dominant signature was where H3K4me3 / H3K18ac co-localized with both 
endogenous and exogenous (Fig. 4c-d), we observed numerous locations where the PTM combinatorial overlapped only with exogenous (as at B4GALT2 in Fig. 4d), while the contrasting pattern (PTMs only overlapped with endogenous) was a much rarer species. This may be due to the relative level of exogenous to endogenous protein (or the target PTMs), where one might expect a higher abundance exogenous to extend to locations of lower PTM density. However peak structure comparison does not appear to support this explanation, as sites retaining exogenous but lacking endogenous are not the weakest H3K4me3 / H3K18ac locations. We speculate the more interesting possibility: endogenous BPTF is subject to regulation that further refines its chromatin localization beyond simple availability of H3K4me3 / H3K18ac for its C-terminal PHD-BD. Indeed, there are increasing examples of auto-regulatory elements within CAPs that modulate their activity $^{64-78}$, suggesting that a histone code is more than the simple availability of potentially redundant positive signals.

It is becoming increasingly clear that we should interrogate the binding of readers to histone PTMs with more physiological entities: moving away from minimal-domain queries and histone peptide targets to full length CAPs (or higher order complexes) and Nucs, and thus accommodate the regulatory potential on each side. Doubtless a more thorough mechanistic understanding will reveal novel approaches to target these interactors with therapeutic intent. 


\section{COMPETING INTERESTS}

EpiCypher $^{\circledR}$ is a commercial developer and supplier of reagents (e.g. PTM-defined semisynthetic nucleosomes; dNucs and versaNucs $\left.{ }^{\circledR}\right)$ and platforms (dCypher ${ }^{\circledR}$, CUTANA ${ }^{\circledR}$ CUT\&RUN) used in this study.

\section{AUTHOR CONTRIBUTIONS}

MRM, IKP, AV and NWH designed, performed and analyzed dCypher studies. MJM, RW, SAH and MAC created / validated PTM-defined histones, octamers and nucleosomes. JMB created versaNucs with peptides validated by SAH. KN, EM and BJV performed CUT\&RUN studies. HAF performed NMR and MS analyses under supervision by CM. ZWS and MCK supervised research at EpiCypher. MCK and CM co-wrote the manuscript with contributions / support from all authors.

\section{ACKNOWLEDGEMENTS}

HAF was supported by an NIH T32 fellowship (2T32GM008365-26A1) through the Center for Biocatalysis and Bioprocessing. This project was supported by The Holden Comprehensive Cancer Center at The University of Iowa and its National Cancer Institute Award (P30CA086862). Work in the Musselman lab was funded by grants from the National Science Foundation (CAREER-1452411) and the National Institutes of Health (NIH; R35GM128705). EpiCypher is supported by NIH grants R44GM117683, R44CA214076, R44GM116584 and R44DE029633. We would like to thank Vic Parcell and the High-Resolution Mass Spectrometry Facility (Office of the Vice-President for Research and Economic Development at the University of Iowa) for technical support. 


\section{METHODS}

BPTF protein constructs and preparation. Human BPTF (Uniprot Q12830) PHD fingerbromodomain (PHD-BD) and PHD finger were cloned into pGEX6p with an N-terminal Glutathione S-Transferase (GST) tag and a PreScission Protease cleavage site (Suppl. Tables 3: Resources A and Extended Data Fig. 9). BPTF BD with an N-terminal 6xHistidine (6His) tag and Tobacco Etch Virus (TEV) Protease cleavage site was from Addgene (plasmid 39111). This was modified using the Q5 Site-directed mutagenesis kit (New England Biolabs [NEB]) for domain addition / removal or single amino acid substitutions. All constructs were expressed in E.coli BL21 (DE3) (ThermoFisher Scientific or NEB). Cells were grown to $\mathrm{OD}_{600} \sim 1.0$ and induced with 0.8 mM IPTG at $18^{\circ} \mathrm{C}$ for $\sim 16 \mathrm{hr}$ in LB (or M9 minimal media for NMR). M9 media was supplemented with vitamin (Centrum Adult), $1 \mathrm{~g} / \mathrm{L}^{15} \mathrm{NH}_{4} \mathrm{Cl}$, and $5 \mathrm{~g} / \mathrm{L}$ D-glucose. For constructs containing the BPTF PHD finger all growth media and buffers were supplemented with $100 \mu \mathrm{M} \mathrm{ZnCl}$. For purification of BPTF recombinants cells were lysed by sonication, and lysates incubated with either glutathione agarose (Thermofisher Scientific) or Ni-NTA resin (Thermofisher Scientific) to respectively enrich for GST- and 6His-tagged proteins. Fusion proteins were eluted with reduced L-glutathione or imidazole as appropriate. For NMR, samples were cleaved from the GST tag using PreScission Protease. All BPTF proteins were then further purified using anion exchange (Source 15Q, GE Healthcare Life Sciences) and size exchange chromatography (Superdex 75, GE Healthcare Life Sciences). Protein concentrations were determined by UV-Vis spectroscopy.

Histone preparation and nucleosome core particle reconstitution for NMR. Unmodified human histones H2A, H2B, and H3 (Resource Table A) were expressed in E.coli Rosetta 2 (DE3) $p L y s S$ or BL21 (DE3) in LB media. Cells were grown to $\mathrm{OD}_{600} \sim 0.4$ and induced with $0.4 \mathrm{mM}$ IPTG at $37^{\circ} \mathrm{C}$ for either $3 \mathrm{hr}$ (for H3) or $4 \mathrm{hr}$ (for H2A and H2B). ${ }^{15} \mathrm{~N}$-labelled histone H4 (Suppl. Tables 3: Resources A) was expressed in Rosetta 2 (DE3) pLysS cells from a pET3a vector in M9 minimal media supplemented with vitamin, $1 \mathrm{~g} / \mathrm{L}{ }^{15} \mathrm{NH}_{4} \mathrm{Cl}$, and $5 \mathrm{~g} / \mathrm{L}$ D-glucose. Cells were induced at $\mathrm{OD}_{600} \sim 0.4$ with $0.2 \mathrm{mM}$ IPTG at $37^{\circ} \mathrm{C}$ for $3 \mathrm{hr}$. Histones were purified from inclusion bodies as previously ${ }^{79}$ and purified by ion exchange. Mass spectrometry with positive electrospray ionization (Waters Q-Tof Premier instrument) was used to validate the histones and ensure no carbamylation occurred during purification (Extended Data Fig. 8). Samples were diluted 1:2 or 
1:4 in water/acetonitrile (1:1) with $0.1 \%(\mathrm{v} / \mathrm{v})$ formic acid. The acquisition and deconvolution software used during data collection and analysis were MassLynx and MaxEnt, respectively.

Histone octamers were prepared as described ${ }^{79}$. In brief, equimolar ratios of purified histones were combined in $20 \mathrm{mM}$ Tris $\mathrm{pH}$ 7.5, 6M Guanidine $\mathrm{HCl}, 10 \mathrm{mM}$ DTT and subsequently dialyzed into $20 \mathrm{mM}$ Tris $\mathrm{pH} 7.5,2 \mathrm{M} \mathrm{KCl}, 1 \mathrm{mM}$ EDTA, $5 \mathrm{mM} \beta$-mercaptoethanol ( $\beta$-ME). Octamers were purified via size chromatography over a Sephacryl S-200 column (GE Healthcare Life Sciences).

The 147 bp Widom 601 nucleosome positioning sequence (NPS) ${ }^{80}$ was amplified in E.coli using a plasmid containing 32 repeats (Suppl. Tables 3: Resources A). DNA was purified by alkaline lysis $^{79}$, the $147 \mathrm{bp} 601$ NPS excised from the plasmid with $E c o R V$, polyethylene glycol precipitated, and further purified over a source 15Q column (GE Healthcare Life Sciences).

Reconstitution of Nucleosome core particles (NCPs; Nucs) with the 147 bp DNA was accomplished by desalting ${ }^{79}$. In brief, octamer and DNA were combined in equimolar amounts in $2 \mathrm{M} \mathrm{KCl}$ and desalted to $150 \mathrm{mM} \mathrm{KCl}$ using a linear gradient over $\sim 48 \mathrm{hr}$. Nucs were heat-shocked at $37^{\circ} \mathrm{C}$ for $30 \mathrm{~min}$ for optimal positioning and purified using a $10-40 \%$ sucrose gradient. Nuc formation was confirmed by sucrose gradient profile and native polyacrylamide gel electrophoresis (see Extended Data Fig. 8). Nuc concentrations were determined by UV-vis spectroscopy (after diluting in $2 \mathrm{M} \mathrm{KCl}$ to disassemble NCPs) using the absorbance from $601 \mathrm{DNA}$ (calculated $\varepsilon_{260}=$ 2,312,300.9 $\left.\mathrm{M}^{-1} \mathrm{~cm}^{-1}\right)$.

H4 tail peptide purification for NMR. The histone H4 tail (residues 1-25 followed by a Cterminal tyrosine for quantification) was expressed from pGEX6p as a fusion protein with an Nterminal GST tag followed by a PreScission Protease cleavage site (Suppl. Tables 3: Resources A). This was overexpressed in E.coli BL21 (DE3) (NEB) grown in M9 minimal media supplemented with vitamin (Centrum daily multivitamin), $1 \mathrm{~g} / \mathrm{L}{ }^{15} \mathrm{NH}_{4} \mathrm{Cl}$, and $5 \mathrm{~g} / \mathrm{L} \mathrm{D}$-glucose. Cells were grown to an $\mathrm{OD}_{600} \sim 1.0$ and induced with $0.5 \mathrm{mM}$ IPTG at $37^{\circ} \mathrm{C}$ for $4 \mathrm{hr}$. The ${ }^{15} \mathrm{~N}-\mathrm{GST}$ H4 peptide fusion was purified on glutathione agarose resin (Thermofisher Scientific), cleaved with PreScission Protease $\left(16 \mathrm{hr}\right.$ incubation at $\left.4^{\circ} \mathrm{C}\right)$, and products resolved by size exclusion chromatography (Superdex 75 10/300; GE Healthcare Life Sciences). Peptide identity was validated by mass spectrometry with positive electrospray ionization (on a Waters Q-Tof Premier). Samples were diluted $1: 2$ or $1: 4$ in water/acetonitrile $(1: 1)$ with $0.1 \%$ formic acid. The acquisition 
and deconvolution software used during data collection and analysis were MassLynx and MaxEnt, respectively. ${ }^{15} \mathrm{~N}-\mathrm{H} 4$ (1-25) peptide concentration was determined by UV-vis spectroscopy using the non-native C-terminal tyrosine.

DNA preparation for NMR. Oligonucleotides (5'-CTCAATTGGTCGTAGACAGCT-3' and the complement 5'-AGCTGTCTACGAACCAATTGAG-3') for DNA titration NMR were from Integrated DNA Technologies (IDT). These were annealed at $50 \mu \mathrm{M}$ by heating to $94^{\circ} \mathrm{C}$ followed by gradual cooling to room temperature (in $10 \mathrm{mM}$ Tris- $\mathrm{HCl} \mathrm{pH}$ 7.5, $50 \mathrm{mM} \mathrm{NaCl}, 1 \mathrm{mM} \mathrm{EDTA}$ ). Duplex DNA was purified by ion exchange chromatography on a source 15Q column (GE Healthcare Life Sciences) and analyzed by 1\% agarose gel. DNA was precipitated in ethanol, resuspended in $\mathrm{ddH}_{2} \mathrm{O}$, and concentration determined by UV-vis spectroscopy and the predicted extinction coefficient $\left(\varepsilon_{260}=333,804.5 \mathrm{M}^{-1} \mathrm{~cm}^{-1}\right)$.

NMR spectroscopy. ${ }^{1} \mathrm{H}-{ }^{15} \mathrm{~N}$ heteronuclear single quantum coherence (HSQC) spectra were collected on $30 \mu \mathrm{M}{ }^{15} \mathrm{~N}-\mathrm{H} 4$ tail peptide and $80.5 \mu \mathrm{M}$ nucleosome samples in $20 \mathrm{mM} \mathrm{MOPS} \mathrm{pH}$ 7.2, $150 \mathrm{mM} \mathrm{KCl}, 1 \mathrm{mM}$ DTT, $1 \mathrm{mM}$ EDTA, and $10 \% \mathrm{D}_{2} \mathrm{O}$. Data was collected at $25^{\circ} \mathrm{C}$ on an $800 \mathrm{MHz}$ Bruker spectrometer equipped with a cryoprobe. Titration of the $21 \mathrm{bp}$ dsDNA into ${ }^{15} \mathrm{~N}-$ $\mathrm{H} 4$ tail peptide was performed through the collection of sequential ${ }^{1} \mathrm{H}^{15} \mathrm{~N}$ HSQC spectra on the ${ }^{15} \mathrm{~N}-\mathrm{H} 4$ tail in the apo state and with increasing DNA concentrations (spectra collected at [peptide:DNA] molar ratios of 1:0, 1:0.1, 1:0.25, 1:0.5, 1:1, 1:2, and 1:3).

Sequential ${ }^{1} \mathrm{H}_{-}{ }^{15} \mathrm{~N}$ HSQC spectra of $25 \mu \mathrm{M}{ }^{15} \mathrm{~N}-\mathrm{BD}$ and ${ }^{15} \mathrm{~N}-\mathrm{BD}(\mathrm{N} 3007 \mathrm{~A})$ were collected with increasing concentrations of H4K16ac tail peptide (Suppl. Tables 3: Resources D) in 50 $\mathrm{mM}$ potassium phosphate $\mathrm{pH} 7.2,50 \mathrm{mM} \mathrm{KCl}, 1 \mathrm{mM}$ DTT, $1 \mathrm{mM}$ EDTA, and $10 \% \mathrm{D}_{2} \mathrm{O}$ at $25^{\circ} \mathrm{C}$ on an $800 \mathrm{MHz}$ Bruker spectrometer equipped with a cryogenic probe. Concentration of the stock H4K16ac peptide was analyzed by Pierce Quantitative Fluorometric Peptide Assay (Thermofisher Scientific). Spectra were collected with $\left[{ }^{15} \mathrm{~N}-\mathrm{BD}\right.$ : H4K16ac peptide] at ratios 1:0, 1:0.5, 1:1, 1:2.5, 1:5, 1:10, 1:20, 1:30, 1:50, 1:70 and [ ${ }^{15} \mathrm{~N}-\mathrm{BD}$ (N3007A): H4K16ac peptide] at ratios 1:0, 1:5, 1:20, 1:40.

Sequential ${ }^{1} \mathrm{H}_{-}{ }^{15} \mathrm{~N}$ HSQC spectra of $50 \mu \mathrm{M}{ }^{15} \mathrm{~N}-\mathrm{PHD}-\mathrm{BD}$ were collected with increasing concentrations of histone tail peptides $\left(\mathrm{H} 3 \mathrm{~K} 4 \mathrm{me} 3 \mathrm{tri}^{\mathrm{ac}}\right.$, $\mathrm{H} 3 \mathrm{tetra}^{\mathrm{ac}}$ or $\left.\mathrm{H} 3 \mathrm{tri}^{\mathrm{ac}}\right)$ were collected in 50 $\mathrm{mM}$ potassium phosphate $\mathrm{pH}$ 7.2, $50 \mathrm{mM} \mathrm{KCl}, 1 \mathrm{mM}$ DTT, $25 \mu \mathrm{M} \mathrm{ZnCl} 2$, and $10 \% \mathrm{D}_{2} \mathrm{O}$. 
Experiments were collected at $25^{\circ} \mathrm{C}$ on an $800 \mathrm{MHz}$ Bruker spectrometer equipped with a cryogenic probe. Data was collected for $\left[{ }^{15} \mathrm{~N}-\mathrm{PHD}-\mathrm{BD}\right.$ : H3 tail peptide] at ratios 1:0, 1:0.1, 1:0.5, 1:1, 1:2, 1:4, and 1:8. All NMR data was processed using NMRPipe ${ }^{81}$ and analyzed using CcpNmr Analysis ${ }^{82}$.

Histone peptides for $\mathbf{d C y p h e r . ~ A l l ~ h i s t o n e ~ p e p t i d e s ~ f o r ~} d$ Cypher (Suppl. Tables 3: Resources B) were synthesized with a terminal Biotin (location as indicated) and identity confirmed by mass spectrometry.

Semi-synthetic nucleosomes with defined post-translational modifications (PTMs). PTMdefined histones, octamers and nucleosomes $\left[\mathrm{dNucs}^{\mathrm{TM}}\right.$ or versaNucs ${ }^{\circledR}$ ] for $d$ Cypher were synthesized / purified / assembled as previously ${ }^{83,84}$ but without DNA barcoding (see Suppl. Discussion; Suppl. Tables 3: Resources C - D; and Extended Data Fig. 9).

dCypher binding assays. $d$ Cypher binding assays to PTM-defined peptides / Nucs were performed

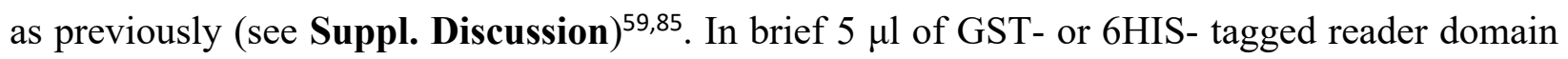
(Query: specific identity / concentration as indicated) was incubated with $5 \mu$ of biotinylated peptide (100 nM final) / Nuc (10 nM final) (Target: specific identity as indicated) for $30 \mathrm{~min}$ at room temperature in the appropriate assay buffer ([Peptide: $50 \mathrm{mM}$ Tris $\mathrm{pH} 7.5,50 \mathrm{mM} \mathrm{NaCl}$, 0.01\% Tween-20, 0.01\% BSA, 0.0004\% Poly-L Lysine, 1mM TCEP]; [Nuc: 20mM HEPES pH 7.5, 250mM NaCl, 0.01\% BSA, 0.01\% NP-40, 1mM DTT]) in a 384-well plate. For GST-tagged proteins a $10 \mu \mathrm{lmix}$ of $2.5 \mu \mathrm{g} / \mathrm{ml}$ glutathione (PerkinElmer) and $5 \mu \mathrm{g} / \mathrm{ml}$ streptavidin donor beads (PerkinElmer) was prepared in peptide or Nuc bead buffer ([Peptide: as assay buffer]; [Nucs: as assay buffer minus DTT]) and added to each well. For 6HIS-tagged proteins a $10 \mu \mathrm{mix}$ of 2.5 $\mu \mathrm{g} / \mathrm{ml}$ Ni-NTA acceptor beads (PerkinElmer) and $10 \mu \mathrm{g} / \mathrm{ml}$ streptavidin donor beads was used. The plate was incubated at room temperature in subdued lighting for $60 \mathrm{~min}$ and the Alpha signal measured on a PerkinElmer 2104 EnVision (680-nm laser excitation, 570-nm emission filter \pm 50 $\mathrm{nm}$ bandwidth). Each binding interaction was performed in duplicate ${ }^{86}$.

Binding curves [Query : Target] were generated using a non-linear 4PL curve fit in Prism 8 (GraphPad), with $\mathrm{EC}_{50}{ }^{\text {rel }}$ values and $95 \%$ confidence intervals $\left(\mathrm{CI}^{95}\right)$ computed and converted from $\log (\mathrm{X})$ using antilog $10^{\wedge} \mathrm{X}$ (see Suppl. Discussion and Suppl. Tables 1 \& 2). Where 
necessary, values beyond the Alpha hook point (indicating bead saturation / competition with unbound Query) ${ }^{86}$ were excluded and top signal constrained to average max signal for Target (in cases where signal never reached plateau, those were constrained to the average max signal within the assay). For statistical analysis, unpaired two-tailed t-tests were performed in Prism using $\log \left(\mathrm{EC}_{50}{ }^{\mathrm{rel}}\right)$ and standard error values / differences considered statistically significantly when $\mathrm{P}<$ 0.05 (see Suppl. Tables 1 \& 2).

CUTANA CUT\&RUN, Illumina sequencing, and data analysis. CUT\&RUN was performed with native or fixed (H3K18ac only; see below) K562 cells using $\underline{\text { UUTANA }}^{\mathrm{TM}}$ protocol v1.5.1 ${ }^{87}$ which is an optimized version of that previously described ${ }^{88}$. For each native CUT\&RUN reaction, $500 \mathrm{~K}$ permeabilized cells were immobilized onto Concanavalin-A beads (Con-A; EpiCypher \#21$1401)$ and incubated overnight ( $4^{\circ} \mathrm{C}$ with gentle rocking) with $0.5 \mu \mathrm{g}$ of antibody (IgG, $\mathrm{H} 3 \mathrm{~K} 4 \mathrm{me} 3$, H3K18ac and BPTF [Suppl. Tables 3: Resources E; all PTM antibodies validated to SNAP-ChIP Nuc standards as previously ${ }^{83}$ ). pAG-MNase (EpiCypher \#15-1016) was added / activated and CUT\&RUN enriched DNA purified using the Monarch DNA Cleanup kit (NEB \#T1030S). 10 ng DNA was used to prepare sequencing libraries with the Ultra II DNA Library Prep kit (NEB \#E7645S).

Some labile PTMs benefit from a light fixation step (not shown), so minor protocol modifications were made for $\mathrm{H} 3 \mathrm{~K} 18 \mathrm{ac}$. $500 \mathrm{~K}$ cells were crosslinked with $0.1 \%$ formaldehyde for 1 minute at room temperature, and then quenched with $125 \mathrm{mM}$ glycine. To help the cellular ingress of antibody / egress of cleaved chromatin fragments the Wash, Antibody, and Digitonin buffers were supplemented with 1\% Triton X-100 and 0.05\% SDS. To reverse crosslinks prior to DNA column cleanup, CUT\&RUN eluate was incubated overnight at $55^{\circ} \mathrm{C}$ with $0.8 \mu 110 \%$ SDS and $20 \mu \mathrm{g}$ Proteinase K (Ambion \#AM2546).

Libraries were sequenced on the Illumina platform, obtaining $\sim 4$ million paired-end reads on average (Suppl. Tables 3: Resources E). Paired-end fastq files were aligned to the hg19 reference genome using the Bowtie 2 algorithm ${ }^{89}$. Only uniquely aligned reads were retained, and blacklist regions ${ }^{90}$ filtered out prior to subsequent analyses. Peaks were called using SEACR

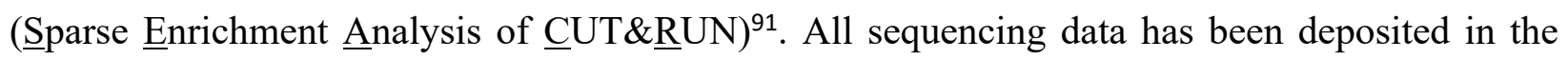
NCBU Gene Expression Omnibus (GEO) with accession number GSE150617. 
Reader CUT\&RUN. Reader CUT\&RUN (i.e. GST-PHD-BD) was performed as above for CUTANA CUT\&RUN with the following modifications.

$500 \mathrm{~K}$ native K562 cells were used for each reaction and all buffers were supplemented with $1 \mu \mathrm{M}$ TSA (Trichstatin A, Sigma \#T8552) to protect potentially labile acetyl-PTMs (e.g. H3K18ac).

A biotinylated CUTANA Nuc mini-panel (unmodified, H3K4me3, H3tetra ${ }^{\text {ac }}$, H3K4me3tri ${ }^{\text {ac}}$; each on 80-N-25 DNA containing a central 147bp Widom 601 Nucleosome positioning sequence with embedded 22bp DNA barcode: Fig. 4a-b) was synthesized, individually coupled to magnetic streptavidin beads (NEB \#S1421S) at saturation, and spiked into each CUT\&RUN reaction (final concentration $0.8 \mathrm{nM}$ ) with Con-A immobilized cells just prior to antibody addition. Each member of the Nuc panel was DNA barcoded to define PTM status / monitor comparative release into the CUT\&RUN eluate (to be quantified after sequencing). After Nuc spike-in, GST-PHD-BD or GST (Suppl. Tables 3: Resources B) and IgG (Suppl. Tables 3: Resources E) were added to the same sample (final concentration $70 \mathrm{nM}$ each), and incubated overnight at $4^{\circ}$ C. Samples were washed twice, and then incubated with $0.5 \mu$ g anti-GST (Suppl. Tables 3: Resources E) at room temperature for $30 \mathrm{~min}$. The remainder of the assay was performed using the standard CUT\&RUN protocol and sequenced as above. All sequencing data has been deposited in GEO with accession number GSE150617. 


\section{FIGURES}

a

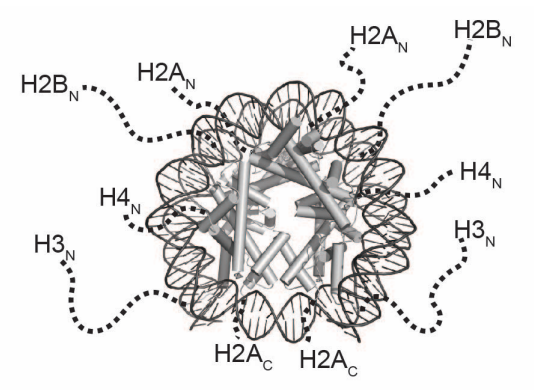

c

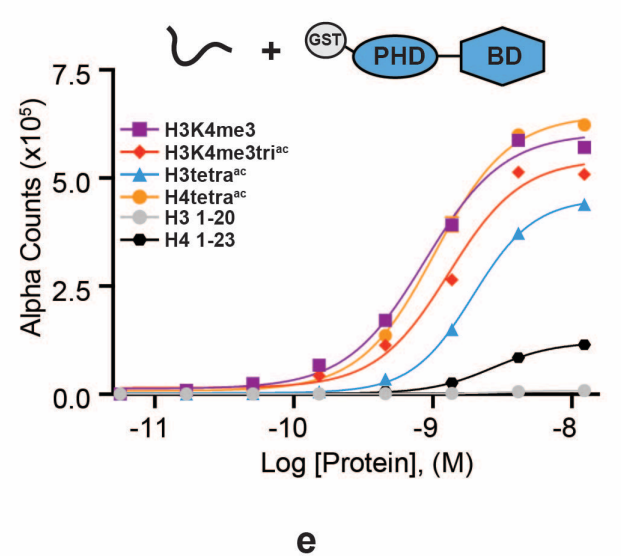

b

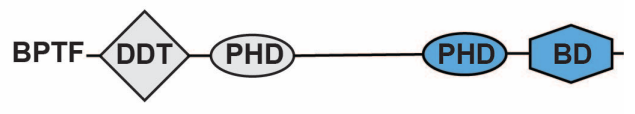

d

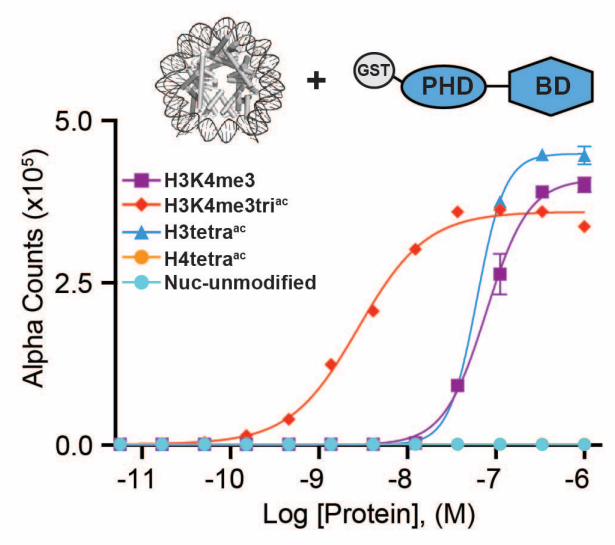

$\mathrm{EC}_{50}{ }^{\mathrm{rel}}(\mathrm{nM})\left(\mathrm{Cl}^{95}\right)$

GST-PHD-BD

\begin{tabular}{lcc}
\multirow{2}{*}{ Modification state } & \multicolumn{2}{c}{ GST-PHD-BD } \\
\cline { 2 - 3 } H3K4me3 & Peptide & Nuc \\
\hline H3K4me2 & $0.88(0.75-1.02)$ & $77.8(69.8-86.9)$ \\
\hline H3K4me1 & $0.36(0.32-0.37)$ & ND \\
\hline H3K4me3tria & $1.3(1.1-1.6)$ & ND \\
\hline H3tetra ${ }^{\text {ac }}$ & $2.4(2.1-2.7)$ & $61.0(59.4-3.2)$ \\
\hline H4tetra & $1.0(0.89-1.1)$ & $\mathrm{ND}$ \\
\hline H3 1-20 & $>100$ & - \\
\hline H4 1-23 & $29.0(20.5-40.1)$ & - \\
\hline Nuc-unmodified & - & $\mathrm{ND}$ \\
\hline
\end{tabular}

Fig. 1. BPTF PHD-BD demonstrates restricted and synergistic PTM binding in the nucleosome vs. peptide context. a) The nucleosome core particle (PDB: 3LZ0) (Nuc): histone $\mathrm{N}$ - and C-terminal tails (as defined by trypsin digest and to relative scale) are depicted as dotted lines. b) Secondary domain architecture of BPTF [Uniprot Q12830; 3,046 aa; $338 \mathrm{kDa}$ ]. Region covered by the C-terminal tandem PHD-BD (aa 2865-3036; as used throughout this study) is in blue. c,d) Alpha counts plotted as a function of GST-PHD-BD Query concentration from dCypher assays with histone peptide (c) or Nuc (d) Targets. e) Relative $\mathrm{EC}_{50}\left(\mathrm{EC}_{50}{ }^{\text {rel }}\right)$ and $95 \%$ confidence interval $\left(\mathrm{CI}^{95}\right)$ values from dCypher curves (in c,d and Extended Data Fig. 1d,e; for calculation see Methods and Suppl. Discussion). Targets are color coded as per legends. ND, Not Determined. 
a
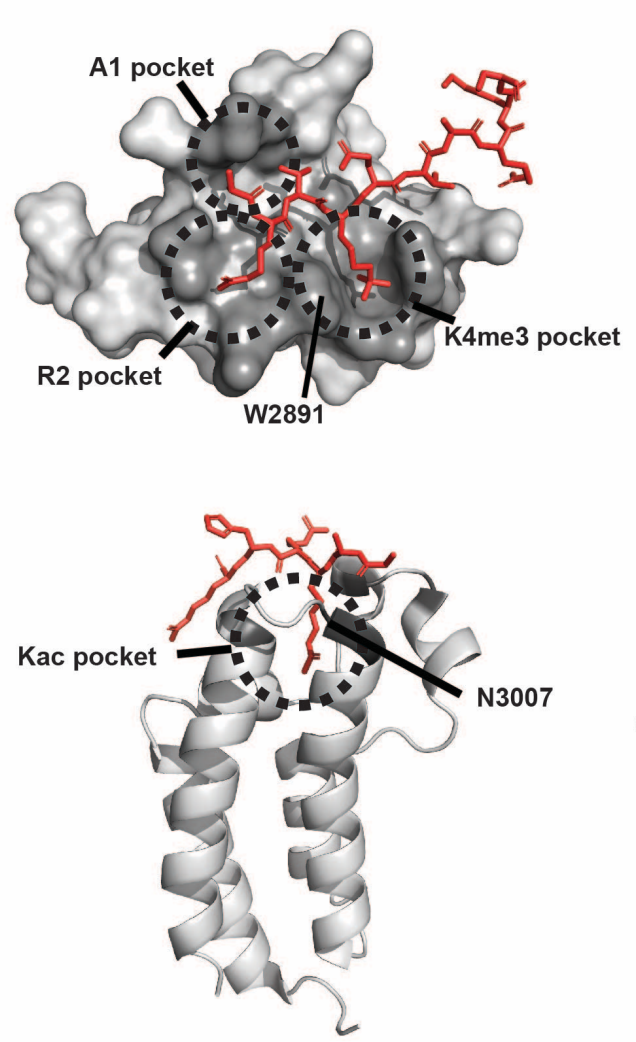

b

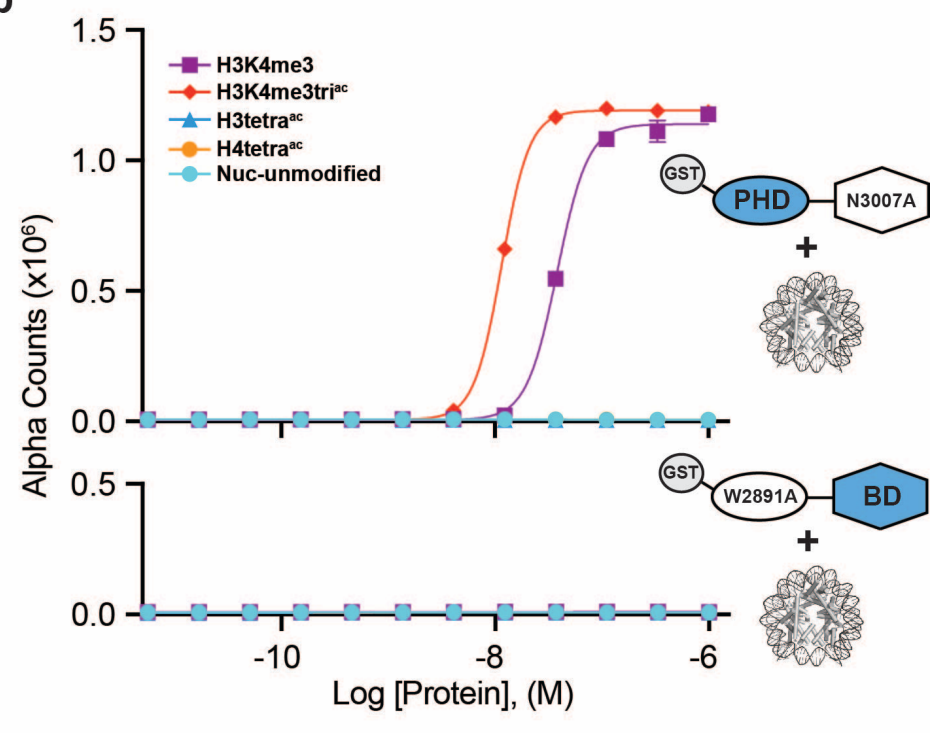

C

\begin{tabular}{|c|c|c|}
\hline \multirow[b]{2}{*}{ Modification State } & \multicolumn{2}{|c|}{$\begin{array}{c}\mathrm{EC}_{50}{ }^{\text {rel }}(\mathrm{nM})\left(\mathrm{Cl}{ }^{95}\right) \\
\text { Nuc }\end{array}$} \\
\hline & GST-PHD-BD $^{\text {mut }}$ & GST-PHD $^{\text {mut }}$-BD \\
\hline H3K4me3 & $38.4(36.8-40.3)$ & ND \\
\hline H3K4me3triac & $11.6(11.4-11.9)$ & ND \\
\hline$\Delta \mathrm{H}_{3}$ tetra & ND & ND \\
\hline H4tetra & ND & ND \\
\hline Nuc-unmodified & ND & ND \\
\hline
\end{tabular}

Fig. 2. BPTF PHD and BD both contribute to Nuc binding. a) The PHD-H3K4me3 (top) and BD-Kac (bottom) binding pockets are highlighted on previously solved structures of the individual domains in complex with histone peptides (PDB: 2FUU and 3QZT). Binding pockets are circled / labeled: on PHD for A1, R2, and K4me3; on BD for Kac. Relative location of PTM-binding residues W2891 (PHD) and N3007 (BD) are also indicated (and mutated to alanine in b, c). b) Alpha Counts from dCypher assays plotted as a function of GST-PHD-BD ${ }^{\text {N3007A }}$ (GST-PHDBD $^{\text {mut; }}$ top) or GST-PHD ${ }^{\text {W2891A }}$-BD (GST-PHD ${ }^{\text {mut }}$-BD; bottom) Query concentration to Nuc Targets. c) $\mathrm{EC}_{50}{ }^{\text {rel }}\left(\mathrm{CI}^{95}\right)$ values from dCypher curves in (b). Targets are color coded as per legends. ND, Not Determined. 
a

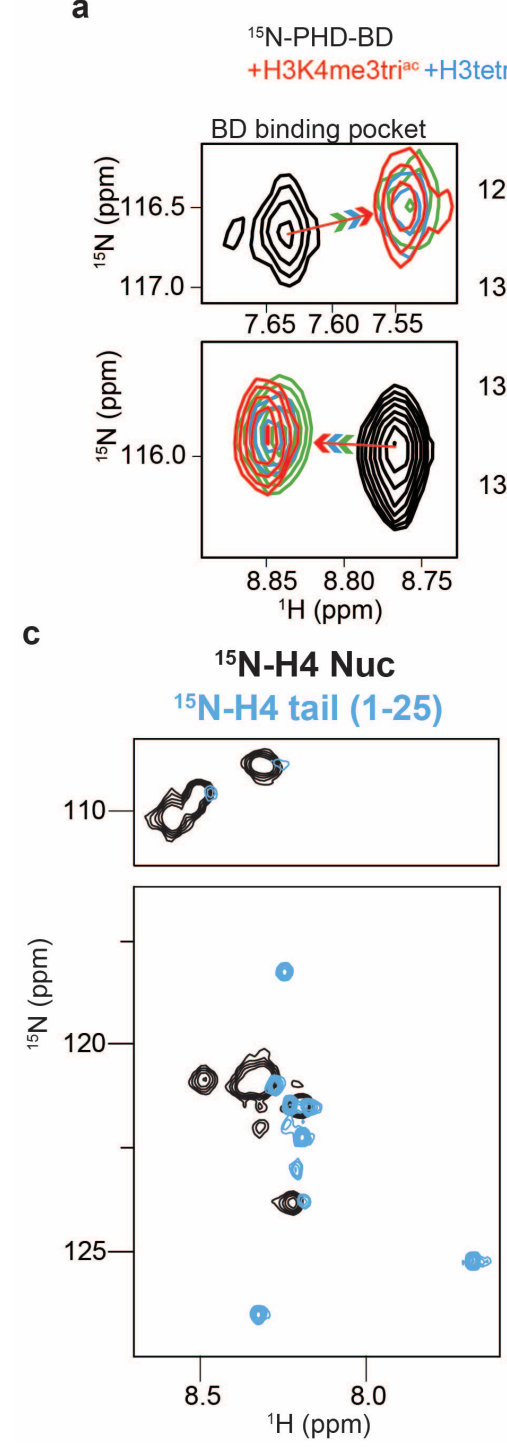

b

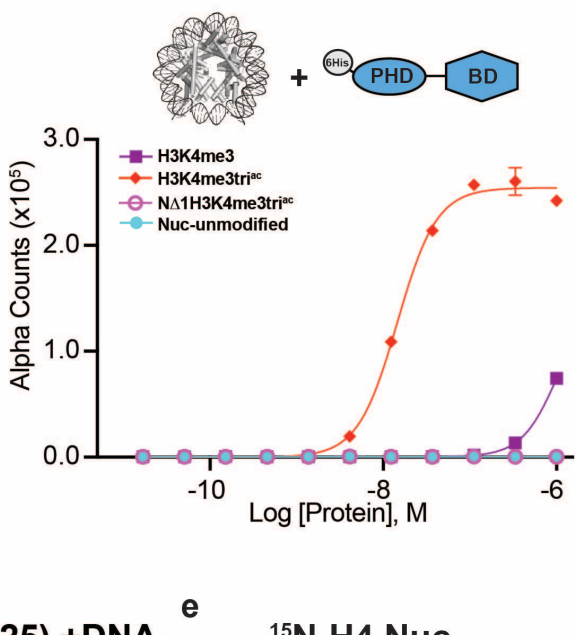

d

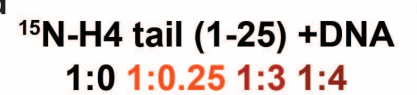

${ }^{15} \mathrm{~N}-\mathrm{H} 4 \mathrm{Nuc}$
${ }^{15} \mathrm{~N}-\mathrm{H} 4$ tail +DNA
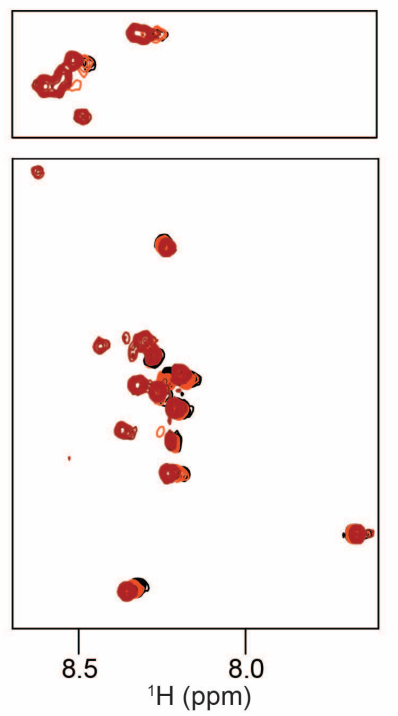
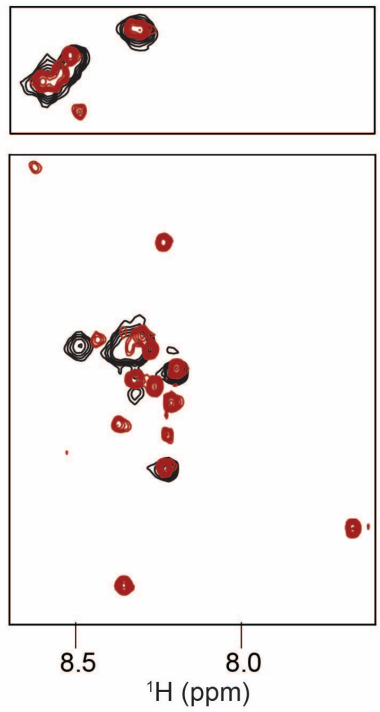

Fig. 3. The preferred PTM binding pattern is dictated by Nuc conformation and multivalent reader binding potential. a) ${ }^{1} \mathrm{H},{ }^{15} \mathrm{~N}-\mathrm{HSQC}$ overlays of ${ }^{15} \mathrm{~N}-\mathrm{PHD}-\mathrm{BD}$ apo (black) or in the presence of H3tri ${ }^{\text {ac }}$ (green), H3tetra ${ }^{\text {ac }}$ (blue), or H3K4me3triac (red). Arrows denote trajectory of chemical shift perturbation and are colored by peptide. Shown are representative resonances for the BD (left) and PHD (right) binding pockets. b) Histone H3-A1 is essential for 6His-PHD-BD binding to Nucs (compare H3K4me3tri ${ }^{\text {ac }}$ to $\mathrm{N} \Delta 1 \mathrm{H} 3 \mathrm{~K} 4 \mathrm{me} 3 \mathrm{tri}^{\mathrm{ac}}$ ). Alpha Counts from dCypher assays are plotted as a function of Query concentration to indicated Nuc Targets. c) Overlay ${ }^{1} \mathrm{H},{ }^{15} \mathrm{~N}-\mathrm{HSQC}$ spectra of ${ }^{15} \mathrm{~N}-\mathrm{H} 4-\mathrm{Nuc}$ (black) and ${ }^{15} \mathrm{~N}-\mathrm{H} 4-$ tail peptide (residues 1-25, blue). d) Overlay ${ }^{1} \mathrm{H},{ }^{15} \mathrm{~N}-\mathrm{HSQC}$ spectra of ${ }^{15} \mathrm{~N}$-H4-tail peptide upon titration of a $21 \mathrm{bp}$ double-stranded DNA. Molar ratios are denoted by color in legend. e) Overlay ${ }^{1} \mathrm{H},{ }^{15} \mathrm{~N}-\mathrm{HSQC}$ spectra of ${ }^{15} \mathrm{~N}-\mathrm{H} 4-$ Nuc (black) and ${ }^{15} \mathrm{~N}-\mathrm{H} 4$-tail peptide saturated with DNA (red). 
a
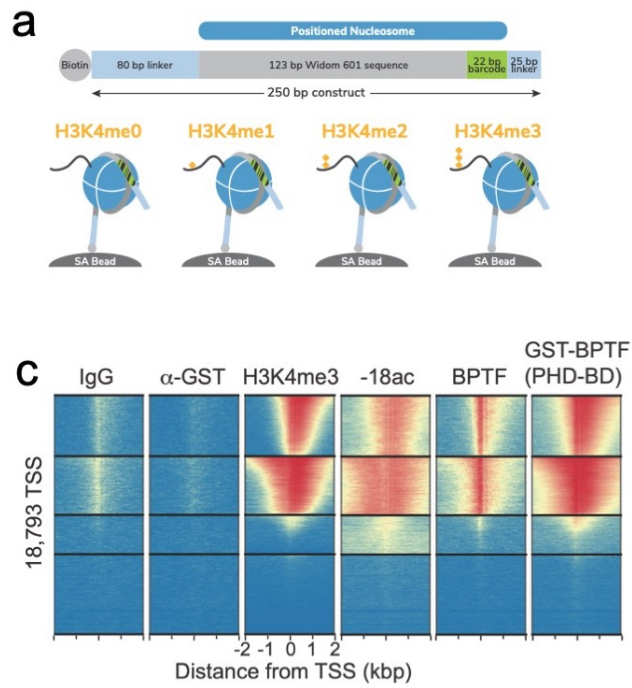
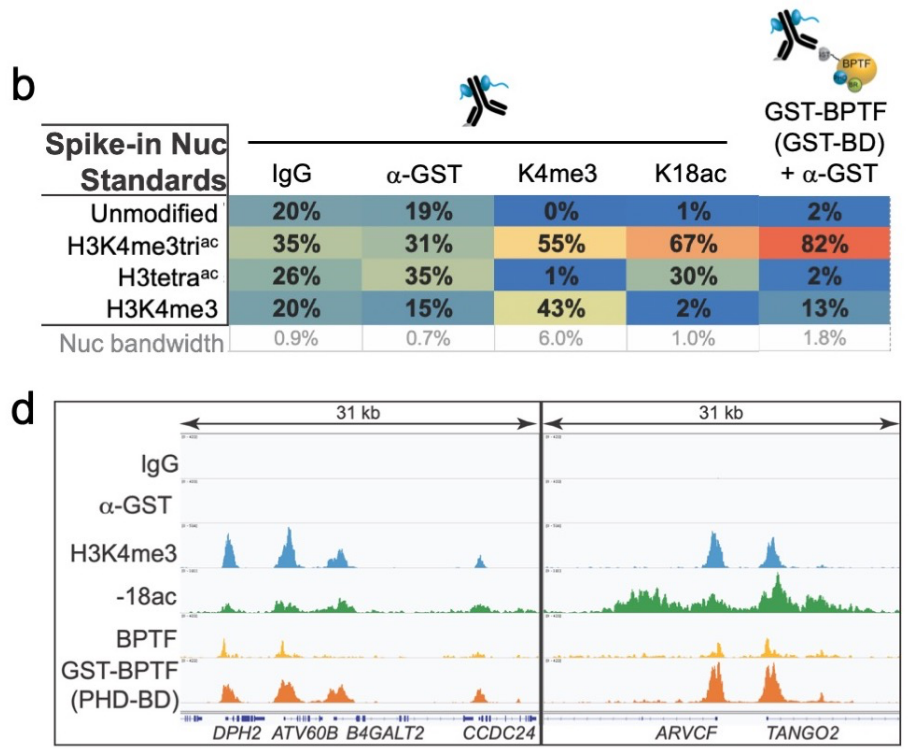

Fig. 4. The in vitro combinatorial preference of BPTF PHD-BD is recapitulated in vivo. a) CUTANA Nuc spike-ins contain a 5 'biotin for immobilization to magnetic beads and a DNA barcode to define PTM status / monitor release into the CUT\&RUN eluate. A four-member panel was assembled to explore GST-PHD-BD binding (unmodified, H3K4me3, H3tetrac, H3K 4me3triac; on 80-N-25 DNA containing a central 147bp 601 Nucleosome positioning sequence with embedded 22bp DNA barcode). b) GST.PHD-BD shows strong preference for spike-in Nucs containing $\mathrm{H} 3 \mathrm{~K} 4 \mathrm{me} 3 \mathrm{tri}^{\mathrm{ac}}$. Table shows relative release of spike-ins (percent barcoded Nuc / total barcode reads) in Reader CUT\&RUN (Methods). Antibodies are noted by column; GST-BPTF (PHD-BD) is detected by $\alpha$-GST to facilitate pAG-MNase recruitment. 'Nuc bandwidth' is the percentage of total sequence reads taken up by Nuc spike-in standards. c) Heatmap of CUT\&RUN signal aligned to the transcription start site (TSS, $+/-2 \mathrm{~kb}$ ) of 18,793 genes in K562 cells. Rows were k-means clustered into four groups (boxed) using ChAsE chromatin analysis too ${ }^{92}$. High and low signal (red and blue respectively) are ranked by / linked to H3K4me3 (top to bottom). d) CUT\&RUN RPKM normalized tracks at representative loci using Integrative Genomics Viewer (IGV, Broad Institute). Note the co-localization of BTPF (endogenous) or GSTPHD-BD (exogenous) with $\mathrm{H} 3 \mathrm{~K} 4 \mathrm{me} 3$ and $\mathrm{H} 3 \mathrm{~K} 18 \mathrm{ac}$; that $\mathrm{H} 3 \mathrm{~K} 18 \mathrm{ac}$ alone is insufficient to recruit BTPF or GST-PHD-BD; and that GST-PHD-BD shows robust recruitment at some locations where BPTF is absent (e.g. B4GALT2 promoter; see Discussion). 


\section{REFERENCES}

1. Luger, K., Mäder, A. W., Richmond, R. K., Sargent, D. F. \& Richmond, T. J. Crystal structure of the nucleosome core particle at $2.8 \AA$ resolution. Nature 389, 251-260 (1997).

2. Wang, Z., Schones, D. E. \& Zhao, K. Characterization of human epigenomes. Current Opinion in Genetics \& Development 19, 127-134 (2009).

3. Zhou, V. W., Goren, A. \& Bernstein, B. E. Charting histone modifications and the functional organization of mammalian genomes : Abstract : Nature Reviews Genetics. Nature Reviews Genetics (2010).

4. Rivera, C. M. \& Ren, B. Mapping Human Epigenomes. Cell (2013).

5. Strahl, B. D. \& Allis, C. D. The language of covalent histone modifications. Nature 403, 4145 (2000).

6. Gardner, K. E., Allis, C. D. \& Strahl, B. D. OPERating ON Chromatin, a Colorful Language where Context Matters. Journal of molecular biology 409, 36-46 (2011).

7. Lee, J.-S., Smith, E. \& Shilatifard, A. The language of histone crosstalk. Cell 142, 682-5 (2010).

8. Rothbart, S. B. \& Strahl, B. D. Interpreting the language of histone and DNA modifications. Biochimica et biophysica acta 1839, 627-643 (2014).

9. Andrews, F. H., Strahl, B. D. \& Kutateladze, T. G. Insights into newly discovered marks and readers of epigenetic information. Nature chemical biology 12, 662-668 (2016).

10. Rando, O. J. Combinatorial complexity in chromatin structure and function: revisiting the histone code. Curr Opin Genet Dev 22, 148-55 (2012).

11. Kelly, T. K., Carvalho, D. D. D. \& Jones, P. A. Epigenetic modifications as therapeutic targets. Nat Biotechnol 28, 1069-78 (2010).

12. Ahuja, N., Sharma, A. R. \& Baylin, S. B. Epigenetic Therapeutics: A New Weapon in the War Against Cancer. Annu Rev Med 67, 73-89 (2016).

13. Önder, Ö., Sidoli, S., Carroll, M. \& Garcia, B. A. Progress in epigenetic histone modification analysis by mass spectrometry for clinical investigations. Expert Rev Proteomic 12, 499-517 (2015).

14. Zaware, N. \& Zhou, M.-M. Chemical modulators for epigenome reader domains as emerging epigenetic therapies for cancer and inflammation. Curr Opin Chem Biol 39, 116-125 (2017). 
15. Patel, D. J. \& Wang, Z. Readout of Epigenetic Modifications. 82, 81-118 (2013).

16. Musselman, C. A., Lalonde, M.-E., Côté, J. \& Kutateladze, T. G. Perceiving the epigenetic landscape through histone readers. Nature structural \& molecular biology 19, 1218-1227 (2012).

17. Ruthenburg, A. J., Li, H., Patel, D. J. \& Allis, C. D. Multivalent engagement of chromatin modifications by linked binding modules. Nature Reviews Molecular Cell Biology 8, 983-994 (2007).

18. Allali-Hassani, A., Kuznetsova, E., Hajian, T., Wu, H., Dombrovski, L., Li, Y., Gräslund, S., Arrowsmith, C. H., Schapira, M. \& Vedadi, M. A Basic Post-SET Extension of NSDs Is Essential for Nucleosome Binding In Vitro. J Biomol Screen 19, 928-35 (2014).

19. Kim, S.-A., Zhu, J., Yennawar, N., Eek, P. \& Tan, S. Crystal Structure of the LSD1/CoREST Histone Demethylase Bound to Its Nucleosome Substrate. Mol Cell 78, 903-914.e4 (2020).

20. Strelow, J. M., Xiao, M., Cavitt, R. N., Fite, N. C., Margolis, B. J. \& Park, K.-J. The Use of Nucleosome Substrates Improves Binding of SAM Analogs to SETD8. J Biomol Screen 21, 786-94 (2016).

21. Stützer, A., Liokatis, S., Kiesel, A., Schwarzer, D., Sprangers, R., Söding, J., Selenko, P. \& Fischle, W. Modulations of DNA Contacts by Linker Histones and Post-translational Modifications Determine the Mobility and Modifiability of Nucleosomal H3 Tails. Molecular Cell 61, 247-259 (2016).

22. Marabelli, C., Marrocco, B., Pilotto, S., Chittori, S., Picaud, S., Marchese, S., Ciossani, G., Forneris, F., Filippakopoulos, P., Schoehn, G., Rhodes, D., Subramaniam, S. \& Mattevi, A. A Tail-Based Mechanism Drives Nucleosome Demethylation by the LSD2/NPAC Multimeric Complex. Cell Reports 27, 387-399.e7 (2019).

23. Morrison, E. A., Bowerman, S., Sylvers, K. L., Wereszczynski, J. \& Musselman, C. A. The conformation of the histone $\mathrm{H} 3$ tail inhibits association of the BPTF PHD finger with the nucleosome. Elife 7, e31481 (2018).

24. Wang, X. \& Hayes, J. J. Site-specific Binding Affinities within the H2B Tail Domain Indicate Specific Effects of Lysine Acetylation. Journal of Biological Chemistry 282, 3286732876 (2007).

25. Gatchalian, J., Wang, X., Ikebe, J., Cox, K. L., Tencer, A. H., Zhang, Y., Burge, N. L., Di, L., Gibson, M. D., Musselman, C. A., Poirier, M. G., Kono, H., Hayes, J. J. \& Kutateladze, T. G. Accessibility of the histone $\mathrm{H} 3$ tail in the nucleosome for binding of paired readers. Nat Commun 8, 1489 (2017).

26. Peng, Y., Li, S., Onufriev, A., Landsman, D. \& Panchenko, A. R. Binding of regulatory proteins to nucleosomes is modulated by dynamic histone tails. Nat Commun 12, 5280 (2021). 
27. Wysocka, J., Swigut, T., Xiao, H., Milne, T. A., Kwon, S. Y., Landry, J., Kauer, M., Tackett, A. J., Chait, B. T., Badenhorst, P., Wu, C. \& Allis, C. D. A PHD finger of NURF couples histone H3 lysine 4 trimethylation with chromatin remodelling. Nature (2006). doi:10.1038/nature04815

28. Li, H., Ilin, S., Wang, W., Duncan, E. M., Wysocka, J., Allis, C. D. \& Patel, D. J. Molecular basis for site-specific read-out of histone $\mathrm{H} 3 \mathrm{~K} 4 \mathrm{me} 3$ by the BPTF PHD finger of NURF. Nature 442, 91-95 (2006).

29. Zahid, H., Olson, N. M. \& Pomerantz, W. C. K. Opportunity knocks for uncovering the new function of an understudied nucleosome remodeling complex member, the bromodomain PHD finger transcription factor, BPTF. Curr Opin Chem Biol 63, 57-67 (2021).

30. Zahid, H., Buchholz, C. R., Singh, M., Ciccone, M. F., Chan, A., Nithianantham, S., Shi, K., Aihara, H., Fischer, M., Schönbrunn, E., Santos, C. O. dos, Landry, J. W. \& Pomerantz, W. C. K. New Design Rules for Developing Potent Cell-Active Inhibitors of the Nucleosome Remodeling Factor (NURF) via BPTF Bromodomain Inhibition. J Med Chem (2021). doi:10.1021/acs.jmedchem.1c01294

31. Li, H., Ilin, S., Wang, W., Duncan, E. M., Wysocka, J., Allis, C. D. \& Patel, D. J. Molecular basis for site-specific read-out of histone $\mathrm{H} 3 \mathrm{~K} 4 \mathrm{me} 3$ by the BPTF PHD finger of NURF. Nature 442, 91-95 (2006).

32. Olson, N., Kroc, S., Johnson, J., Zahid, H., Ycas, P. D., Chan, A., Kimbrough, J., Kalra, P., Schönbrunn, E. \& Pomerantz, W. C. K. NMR Analyses of Acetylated H2A.Z Isoforms Identify Differential Binding Interactions with the Bromodomain of the NURF Nucleosome Remodeling Complex. Biochemistry-us 20, 1871-1880 (2020).

33. Ruthenburg, A. J., Li, H., Milne, T. A., Dewell, S., McGinty, R. K., Yuen, M., Ueberheide, B., Dou, Y., Muir, T. W., Patel, D. J. \& Allis, C. D. Recognition of a Mononucleosomal Histone Modification Pattern by BPTF via Multivalent Interactions. Cell 145, 692-706 (2011).

34. Nguyen, U. T. T., Bittova, L., Müller, M. M., Fierz, B., David, Y., Houck-Loomis, B., Feng, V., Dann, G. P. \& Muir, T. W. Accelerated chromatin biochemistry using DNA-barcoded nucleosome libraries. Nature methods 11, 834-840 (2014).

35. Marunde, M. R., Popova, I. K., Weinzapfel, E. N. \& Keogh, M.-C. Chromatin, Methods and Protocols. Methods Mol Biology 2458, 231-255 (2022).

36. Eglen, R. M., Reisine, T., Roby, P., Rouleau, N., Illy, C., Bossé, R. \& Bielefeld, M. The Use of AlphaScreen Technology in HTS: Current Status. Curr Chem Genom 1, 2-10 (2008).

37. Quinn, A. M., Bedford, M. T., Espejo, A., Spannhoff, A., Austin, C. P., Oppermann, U. \& Simeonov, A. A homogeneous method for investigation of methylation-dependent proteinprotein interactions in epigenetics. Nucleic acids research 38, e11 (2010). 
38. Chen, P., Guo, Z., Chen, C., Tian, S., Bai, X., Zhai, G., Ma, Z., Wu, H. \& Zhang, K. Identification of Dual Histone Modification-Binding Protein Interaction by Combining Mass Spectrometry and Isothermal Titration Calorimetric Analysis. J Adv Res (2019). doi:10.1016/j.jare.2019.11.003

39. Musselman, C. A., Mansfield, R. E., Garske, A. L., Davrazou, F., Kwan, A. H., Oliver, S. S., O'Leary, H., Denu, J. M., Mackay, J. P. \& Kutateladze, T. G. Binding of the CHD4 PHD2 finger to histone $\mathrm{H} 3$ is modulated by covalent modifications. The Biochemical journal 423, 179-187 (2009).

40. Ghoneim, M., Fuchs, H. A. \& Musselman, C. A. Histone Tail Conformations: A Fuzzy Affair with DNA. Trends Biochem Sci (2021). doi:10.1016/j.tibs.2020.12.012

41. Rabdano, S. O., Shannon, M. D., Izmailov, S. A., Salguero, N. G., Zandian, M., Purusottam, R. N., Poirier, M. G., Skrynnikov, N. R. \& Jaroniec, C. P. Histone H4 Tails in Nucleosomes: a Fuzzy Interaction with DNA. Angewandte Chemie Int Ed 60, 6480-6487 (2021).

42. Zhou, B.-R., Feng, H., Ghirlando, R., Kato, H., Gruschus, J. \& Bai, Y. Histone H4 K16Q mutation, an acetylation mimic, causes structural disorder of its $\mathrm{N}$-terminal basic patch in the nucleosome. Journal of molecular biology 421, 30-37 (2012).

43. Böhm, L. \& Crane-Robinson, C. Proteases as structural probes for chromatin: the domain structure of histones. Bioscience Rep 4, 365-86 (1984).

44. Zheng, C. \& Hayes, J. J. Structures and interactions of the core histone tail domains. Biopolymers 68, 539-546 (2003).

45. Murphy, K. J., Cutter, A. R., Fang, H., Postnikov, Y. V., Bustin, M. \& Hayes, J. J. HMGN1 and 2 remodel core and linker histone tail domains within chromatin. Nucleic acids research 45, 9917-9930 (2017).

46. Karch, K. R., Coradin, M., Zandarashvili, L., Kan, Z.-Y., Gerace, M., Englander, S. W., Black, B. E. \& Garcia, B. A. Hydrogen-Deuterium Exchange Coupled to Top- and Middle-Down Mass Spectrometry Reveals Histone Tail Dynamics before and after Nucleosome Assembly. Structure 26, 1651-1663.e3 (2018).

47. Mullahoo, J., Zhang, T., Clauser, K., Carr, S. A., Jaffe, J. D. \& Papanastasiou, M. Dual protease type XIII/pepsin digestion offers superior resolution and overlap for the analysis of histone tails by HX-MS. Methods (2020). doi:10.1016/j.ymeth.2020.01.016

48. Fuxreiter, M. Fuzziness in Protein Interactions-A Historical Perspective. J Mol Biol 430, 2278-2287 (2018).

49. Tompa, P. \& Fuxreiter, M. Fuzzy complexes: polymorphism and structural disorder in protein-protein interactions. Trends Biochem Sci 33, 2-8 (2008). 
50. Filippakopoulos, P., Picaud, S., Mangos, M., Keates, T., Lambert, J.-P., Barsyte-Lovejoy, D., Felletar, I., Volkmer, R., Müller, S., Pawson, T., Gingras, A.-C., Arrowsmith, C. H. \& Knapp, S. Histone recognition and large-scale structural analysis of the human bromodomain family. Cell 149, 214-231 (2012).

51. Morgan, M. A. J., Popova, I. K., Vaidya, A., Burg, J. M., Marunde, M. R., Rendleman, E. J., Dumar, Z. J., Watson, R., Meiners, M. J., Howard, S. A., Khalatyan, N., Vaughan, R. M., Rothbart, S. B., Keogh, M.-C. \& Shilatifard, A. A trivalent nucleosome interaction by PHIP/BRWD2 is disrupted in neurodevelopmental disorders and cancer. Gene Dev (2021). doi:10.1101/gad.348766.121

52. Miller, T. C. R., Simon, B., Rybin, V., Grötsch, H., Curtet, S., Khochbin, S., Carlomagno, T. \& Müller, C. W. A bromodomain-DNA interaction facilitates acetylation-dependent bivalent nucleosome recognition by the BET protein BRDT. Nature communications 7, 13855 (2016).

53. Mutskov, V., Gerber, D., Angelov, D., Ausio, J., Workman, J. \& Dimitrov, S. Persistent interactions of core histone tails with nucleosomal DNA following acetylation and transcription factor binding. Molecular and cellular biology 18, 6293-6304 (1998).

54. Eidahl, J. O., Crowe, B. L., North, J. A., McKee, C. J., Shkriabai, N., Feng, L., Plumb, M., Graham, R. L., Gorelick, R. J., Hess, S., Poirier, M. G., Foster, M. P. \& Kvaratskhelia, M. Structural basis for high-affinity binding of LEDGF PWWP to mononucleosomes. Nucleic Acids Res 41, 3924-3936 (2013).

55. Nuland, R. van, Schaik, F. M. van, Simonis, M., Heesch, S. van, Cuppen, E., Boelens, R., Timmers, H. M. \& Ingen, H. van. Nucleosomal DNA binding drives the recognition of H3K36methylated nucleosomes by the PSIP1-PWWP domain. Epigenetics \& chromatin 6, 12 (2013).

56. Wang, H., Farnung, L., Dienemann, C. \& Cramer, P. Structure of H3K36-methylated nucleosome-PWWP complex reveals multivalent cross-gyre binding. Nat Struct Mol Biol 27, 16 (2019).

57. Dukatz, M., Holzer, K., Choudalakis, M., Emperle, M., Lungu, C., Bashtrykov, P. \& Jeltsch, A. H3K36me2/3 binding and DNA binding of the DNA methyltransferase DNMT3A PWWP domain both contribute to its chromatin interaction. J Mol Biol 431, 5063-5074 (2019).

58. Tian, W., Yan, P., Xu, N., Chakravorty, A., Liefke, R., Xi, Q. \& Wang, Z. The HRP3 PWWP domain recognizes the minor groove of double-stranded DNA and recruits HRP3 to chromatin. Nucleic acids research 47, 5436-5448 (2019).

59. Weinberg, D. N., Papillon-Cavanagh, S., Chen, H., Yue, Y., Chen, X., Rajagopalan, K. N., Horth, C., McGuire, J. T., Xu, X., Nikbakht, H., Lemiesz, A. E., Marchione, D. M., Marunde, M. R., Meiners, M. J., Cheek, M. A., Keogh, M.-C., Bareke, E., Djedid, A., Harutyunyan, A. S., Jabado, N., Garcia, B. A., Li, H., Allis, C. D., Majewski, J. \& Lu, C. The histone mark H3K36me2 recruits DNMT3A and shapes the intergenic DNA methylation landscape. Nature 573, 281-286 (2019). 
60. Dilworth, D., Hanley, R. P., Freitas, R. F. de, Allali-Hassani, A., Zhou, M., Mehta, N., Marunde, M. R., Ackloo, S., Machado, R. A. C., Yazdi, A. K., Owens, D. D. G., Vu, V., Nie, D. Y., Alqazzaz, M., Marcon, E., Li, F., Chau, I., Bolotokova, A., Qin, S., Lei, M., Liu, Y., Szewczyk, M. M., Dong, A., Kazemzadeh, S., Abramyan, T., Popova, I. K., Hall, N. W., Meiners, M. J., Cheek, M. A., Gibson, E., Kireev, D., Greenblatt, J. F., Keogh, M.-C., Min, J., Brown, P. J., Vedadi, M., Arrowsmith, C. H., Barsyte-Lovejoy, D., James, L. I. \& Schapira, M. A chemical probe targeting the PWWP domain alters NSD2 nucleolar localization. Nat Chem Biol 18, 56-63 (2022).

61. Weaver, T., Morrison, E. \& Musselman, C. Reading More than Histones: The Prevalence of Nucleic Acid Binding among Reader Domains. Molecules 23, 2614-25 (2018).

62. Furukawa, A., Wakamori, M., Arimura, Y., Ohtomo, H., Tsunaka, Y., Kurumizaka, H., Umehara, T. \& Nishimura, Y. Acetylated histone H4 tail enhances histone H3 tail acetylation by altering their mutual dynamics in the nucleosome. P Natl Acad Sci Usa 202010506 (2020). doi:10.1073/pnas.2010506117

63. Morrison, E. A., Baweja, L., Poirier, M. G., Wereszczynski, J. \& Musselman, C. A. Nucleosome composition regulates the histone $\mathrm{H} 3$ tail conformational ensemble and accessibility. Nucleic Acids Res 49, gkab246- (2021).

64. Guo, X., Wang, L., Li, J., Ding, Z., Xiao, J., Yin, X., He, S., Shi, P., Dong, L., Li, G., Tian, C., Wang, J., Cong, Y. \& Xu, Y. Structural insight into autoinhibition and histone H3-induced activation of DNMT3A. Nature 517, 1-20 (2014).

65. Ruan, C., Lee, C.-H., Cui, H., Li, S. \& Li, B. Nucleosome contact triggers conformational changes of Rpd3S driving high-affinity H3K36me nucleosome engagement. Cell reports 10, 204-215 (2015).

66. Lu, C., Ward, A., Bettridge, J., Liu, Y. \& Desiderio, S. An autoregulatory mechanism imposes allosteric control on the $\mathrm{v}(\mathrm{d}) \mathrm{j}$ recombinase by histone h3 methylation. Cell reports 10, 29-38 (2015).

67. Misaki, T., Yamaguchi, L., Sun, J., Orii, M., Nishiyama, A. \& Nakanishi, M. The replication foci targeting sequence (RFTS) of DNMT1 functions as a potent histone H3 binding domain regulated by autoinhibition. Biochem Bioph Res Co 470, 741-747 (2016).

68. Andrews, F. H., Tong, Q., Sullivan, K. D., Cornett, E. M., Zhang, Y., Ali, M., Ahn, J., Pandey, A., Guo, A. H., Strahl, B. D., Costello, J. C., Espinosa, J. M., Rothbart, S. B. \& Kutateladze, T. G. Multivalent Chromatin Engagement and Inter-domain Crosstalk Regulate MORC3 ATPase. Cell reports 16, 3195-3207 (2016).

69. Harrison, J. S., Cornett, E. M., Goldfarb, D., DaRosa, P. A., Li, Z. M., Yan, F., Dickson, B. M., Guo, A. H., Cantu, D. V., Kaustov, L., Brown, P. J., Arrowsmith, C. H., Erie, D. A., Major, M. B., Klevit, R. E., Krajewski, K., Kuhlman, B., Strahl, B. D. \& Rothbart, S. B. Hemi- 
methylated DNA regulates DNA methylation inheritance through allosteric activation of $\mathrm{H3}$ ubiquitylation by UHRF1. eLife 5, (2016).

70. Ludwigsen, J., Pfennig, S., Singh, A. K., Schindler, C., Harrer, N., Forné, I., Zacharias, M. \& Mueller-Planitz, F. Concerted regulation of ISWI by an autoinhibitory domain and the H4 Nterminal tail. eLife 6, (2017).

71. Isaac, R. S., Sanulli, S., Tibble, R., Hornsby, M., Ravalin, M., Craik, C. S., Gross, J. D. \& Narlikar, G. J. Biochemical basis for distinct roles of the heterochromatin proteins Swi6 and Chp2. Journal of molecular biology (2017). doi:10.1016/j.jmb.2017.09.012

72. Slaughter, M. J., Shanle, E. K., McFadden, A. W., Hollis, E. S., Suttle, L. E., Strahl, B. D. \& Davis, I. J. Polybromo-1 (PBRM1) bromodomains variably influence nucleosome interactions and cellular function. The Journal of biological chemistry jbc.RA118.003381-21 (2018). doi:10.1074/jbc.ra118.003381

73. Zhang, Y., Klein, B. J., Cox, K. L., Bertulat, B., Tencer, A. H., Holden, M. R., Wright, G. M., Black, J., Cardoso, M. C., Poirier, M. G. \& Kutateladze, T. G. Mechanism for autoinhibition and activation of the MORC3 ATPase. Proc National Acad Sci 116, 201819524 (2019).

74. Tencer, A. H., Cox, K. L., Wright, G. M., Zhang, Y., Petell, C. J., Klein, B. J., Strahl, B. D., Black, J. C., Poirier, M. G. \& Kutateladze, T. G. Molecular mechanism of the MORC4 ATPase activation. Nat Commun 11, 5466 (2020).

75. Ren, W., Fan, H., Grimm, S. A., Guo, Y., Kim, J. J., Yin, J., Li, L., Petell, C. J., Tan, X.-F., Zhang, Z.-M., Coan, J. P., Gao, L., Cai, L., Detrick, B., Çetin, B., Cui, Q., Strahl, B. D., Gozani, O., Wang, Y., Miller, K. M., O’Leary, S. E., Wade, P. A., Patel, D. J., Wang, G. G. \& Song, J. Direct readout of heterochromatic H3K9me3 regulates DNMT1-mediated maintenance DNA methylation. Proc National Acad Sci 117, 18439-18447 (2020).

76. Ren, W., Fan, H., Grimm, S. A., Kim, J. J., Li, L., Guo, Y., Petell, C. J., Tan, X.-F., Zhang, Z.-M., Coan, J. P., Yin, J., Kim, D. I., Gao, L., Cai, L., Khudaverdyan, N., Çetin, B., Patel, D. J., Wang, Y., Cui, Q., Strahl, B. D., Gozani, O., Miller, K. M., O’Leary, S. E., Wade, P. A., Wang, G. G. \& Song, J. DNMT1 reads heterochromatic H4K20me3 to reinforce LINE-1 DNA methylation. Nat Commun 12, 2490 (2021).

77. Nodelman, I. M., Shen, Z., Levendosky, R. F. \& Bowman, G. D. Autoinhibitory elements of the Chd1 remodeler block initiation of twist defects by destabilizing the ATPase motor on the nucleosome. Proc National Acad Sci 118, e2014498118 (2021).

78. Weinberg, D. N., Rosenbaum, P., Chen, X., Barrows, D., Horth, C., Marunde, M. R., Popova, I. K., Gillespie, Z. B., Keogh, M.-C., Lu, C., Majewski, J. \& Allis, C. D. Two competing mechanisms of DNMT3A recruitment regulate the dynamics of de novo DNA methylation at PRC1-targeted CpG islands. Nat Genet 53, 794-800 (2021). 
79. Bao, Y., Chakravarthy, S., Muthurajan, U. M. \& Luger, K. Reconstitution of Nucleosome Core Particles from Recombinant Histones and DNA. Methods in ... (2003).

80. Lowary, P. T. \& Widom, J. New DNA sequence rules for high affinity binding to histone octamer and sequence-directed nucleosome positioning. Journal of molecular biology (1998).

81. Delaglio, F., Grzesiek, S., Vuister, G., Zhu, G., Pfeifer, J. \& Bax, A. NMRPipe: A multidimensional spectral processing system based on UNIX pipes. Journal of Biomolecular NMR 6, (1995).

82. Vranken, W. F., Boucher, W., Stevens, T. J., Fogh, R. H., Pajon, A., Llinas, M., Ulrich, E. L., Markley, J. L., Ionides, J. \& Laue, E. D. The CCPN data model for NMR spectroscopy: development of a software pipeline. Proteins 59, 687-696 (2005).

83. Shah, R. N., Grzybowski, A. T., Cornett, E. M., Johnstone, A. L., Dickson, B. M., Boone, B. A., Cheek, M. A., Cowles, M. W., Maryanski, D., Meiners, M. J., Tiedemann, R. L., Vaughan, R. M., Arora, N., Sun, Z.-W., Rothbart, S. B., Keogh, M.-C. \& Ruthenburg, A. J. Examining the Roles of H3K4 Methylation States with Systematically Characterized Antibodies. Mol Cell 72, 162-177.e7 (2018).

84. Thålin, C., Aguilera, K., Hall, N. W., Marunde, M. R., Burg, J. M., Rosell, A., Daleskog, M., Månsson, M., Hisada, Y., Meiners, M. J., Sun, Z., Whelihan, M. F., Cheek, M. A., Howard, S. A., Saxena-Beem, S., Noubouossie, D. F., Key, N. S., Sheikh, S. Z., Keogh, M., Cowles, M. W., Lundström, S., Mackman, N., Wallén, H. \& Johnstone, A. L. Quantification of citrullinated histones: Development of an improved assay to reliably quantify nucleosomal H3Cit in human plasma. J Thromb Haemost 18, 2732-2743 (2020).

85. Jain, K., Fraser, C. S., Marunde, M. R., Parker, M. M., Sagum, C., Burg, J. M., Hall, N., Popova, I. K., Rodriguez, K. L., Vaidya, A., Krajewski, K., Keogh, M.-C., Bedford, M. T. \& Strahl, B. D. Characterization of the plant homeodomain (PHD) reader family for their histone tail interactions. Epigenet Chromatin 13, 3 (2020).

86. Marunde, M. R., Popova, I. K., Weinzapfel, E. N. \& Keogh, M.-C. The dCypher approach to interrogate chromatin reader activity against PTM-defined histone peptides and nucleosomes. Methods Mol Biol

87. Yusufova, N., Kloetgen, A., Teater, M., Osunsade, A., Camarillo, J. M., Chin, C. R., Doane, A. S., Venters, B. J., Portillo-Ledesma, S., Conway, J., Phillip, J. M., Elemento, O., Scott, D. W., Béguelin, W., Licht, J. D., Kelleher, N. L., Staudt, L. M., Skoultchi, A. I., Keogh, M.-C., Apostolou, E., Mason, C. E., Imielinski, M., Schlick, T., David, Y., Tsirigos, A., Allis, C. D., Soshnev, A. A., Cesarman, E. \& Melnick, A. M. Histone H1 loss drives lymphoma by disrupting 3D chromatin architecture. Nature 589, 299-305 (2021).

88. Skene, P. J., Henikoff, J. G. \& Henikoff, S. Targeted in situ genome-wide profiling with high efficiency for low cell numbers. Nat Protoc 13, 1006-1019 (2018). 
89. Langmead, B. \& Salzberg, S. L. Fast gapped-read alignment with Bowtie 2. Nat Methods 9, 357-9 (2012).

90. Amemiya, H. M., Kundaje, A. \& Boyle, A. P. The ENCODE Blacklist: Identification of Problematic Regions of the Genome. Sci Rep-uk 9, 9354 (2019).

91. Meers, M. P., Tenenbaum, D. \& Henikoff, S. Peak calling by Sparse Enrichment Analysis for CUT\&RUN chromatin profiling. Epigenet Chromatin 12, 42 (2019).

92. Younesy, H., Nielsen, C. B., Lorincz, M. C., Jones, S. J. M., Karimi, M. M. \& Möller, T. ChAsE: chromatin analysis and exploration tool. Bioinformatics 32, 3324-3326 (2016). 